ARTICLE

https://doi.org/10.1038/s41467-019-10420-9

\title{
Fast and selective fluoride ion conduction in sub-1- nanometer metal-organic framework channels
}

Xingya Li', Huacheng Zhang (1) ${ }^{1}$, Peiyao Wang ${ }^{2}$, Jue Hou (1) ${ }^{1}$, Jun Lu' ${ }^{1}$, Christopher D. Easton ${ }^{3}$, Xiwang Zhang ${ }^{1}$, Matthew R. Hill,3, Aaron W. Thornton ${ }^{3}$, Jefferson Zhe Liu (1) ${ }^{2}$, Benny D. Freeman (1) ${ }^{4}$, Anita J. Hill (1) ${ }^{3}$, Lei Jiang ${ }^{1,5} \&$ Huanting Wang ${ }^{1}$

Biological fluoride ion channels are sub-1-nanometer protein pores with ultrahigh $\mathrm{F}^{-}$conductivity and selectivity over other halogen ions. Developing synthetic $\mathrm{F}^{-}$channels with biological-level selectivity is highly desirable for ion separations such as water defluoridation, but it remains a great challenge. Here we report synthetic $\mathrm{F}^{-}$channels fabricated from zirconium-based metal-organic frameworks (MOFs), UiO-66-X $\left(\mathrm{X}=\mathrm{H}, \mathrm{NH}_{2}\right.$, and $\left.\mathrm{N}^{+}\left(\mathrm{CH}_{3}\right)_{3}\right)$. These MOFs are comprised of nanometer-sized cavities connected by sub-1-nanometer-sized windows and have specific $\mathrm{F}^{-}$binding sites along the channels, sharing some features of biological $\mathrm{F}^{-}$channels. UiO-66-X channels consistently show ultrahigh $\mathrm{F}^{-}$conductivity up to $\sim 10 \mathrm{~S} \mathrm{~m}^{-1}$, and ultrahigh $\mathrm{F}^{-} / \mathrm{Cl}^{-}$selectivity, from $\sim 13$ to $\sim 240$. Molecular dynamics simulations reveal that the ultrahigh $\mathrm{F}^{-}$conductivity and selectivity can be ascribed mainly to the high $\mathrm{F}^{-}$concentration in the UiO-66 channels, arising from specific interactions between $\mathrm{F}^{-}$ions and $\mathrm{F}^{-}$binding sites in the MOF channels.

\footnotetext{
${ }^{1}$ Department of Chemical Engineering, Monash University, Clayton, VIC 3800, Australia. ${ }^{2}$ Department of Mechanical Engineering, The University of Melbourne, Parkville, VIC 3010, Australia. ${ }^{3}$ Manufacturing, CSIRO, Clayton, VIC 3168, Australia. ${ }^{4}$ Department of Chemical Engineering, The University of Texas at Austin, Austin, TX 78712, USA. ${ }^{5}$ Key Laboratory of Bioinspired Materials and Interfacial Science, Technical Institute of Physics and Chemistry, Chinese Academy of Sciences, 100190 Beijing, People's Republic of China. Correspondence and requests for materials should be addressed to H.Z. (email: huacheng.zhang@monash.edu) or to J.Z.L. (email: zhe.liu@unimelb.edu.au) or to H.W. (email: huanting.wang@monash.edu)
} 
F luoride $\left(\mathrm{F}^{-}\right)$ions are ubiquitous in soil, groundwater and the ocean at levels of $10-100 \mu \mathrm{M}$, posing a chronic threat to microorganisms ${ }^{1}$. Excessive $\left(>1.5 \mathrm{mg} \mathrm{L}^{-1}\right)^{2}$ and prolonged fluoride intake is highly detrimental to human health, leading to dental and skeletal fluorosis or neurological damage ${ }^{3}$. To lower the intracellular $\mathrm{F}^{-}$concentration, fluoride ion channels have evolved in unicellular organisms to selectively transport $\mathrm{F}^{-}$, thereby reducing its concentration to alleviate toxicity ${ }^{4,5}$ (Fig. 1a). Despite the co-existence of $\mathrm{F}^{-}$and other ions of the same valence and similar sizes, such as chloride $\left(\mathrm{Cl}^{-}\right)$ions, which are present at much higher concentration than $\mathrm{F}^{-}$ions in biological systems ${ }^{6}$, the selectivity of $\mathrm{F}^{-}$over $\mathrm{Cl}^{-}$for most biological fluoride ion channels ranges from $\sim 10$ to $10,000^{7}$. The ultrahigh $\mathrm{F}^{-}$selectivity presumably arises from angstrom-sized pores and anion-specific binding affinity with phenylalanine moieties in the $\mathrm{F}^{-}$ion channels ${ }^{7-10}$. Inspired by natural $\mathrm{F}^{-}$ion channels, construction of biomimetic fluoride ion channels within membranes is postulated to be an effective way to enhance the efficiency of $\mathrm{F}^{-}$ion separation and, in turn, water defluoridation. While some efforts have been made to fabricate synthetic ion channels via anionspecific binding affinity, the $\mathrm{F}^{-} / \mathrm{Cl}^{-}$selectivity of these channels is only around $1.8^{11}$, much lower than that of biological $\mathrm{F}^{-}$ion channels. In addition, synthetic nanoporous polymer membranes have been developed to separate fluoride ions from other monovalent anions via electrostatic interaction or anion exchange, exhibiting $\mathrm{F}^{-} / \mathrm{Cl}^{-}$selectivities of only $\sim 1.4^{12}$ and $\sim 0.8^{13}$, respectively. Compared with biological ion channels, the low selectivity of existing synthetic materials is due in part to their large nanopores, which do not provide a small enough confined space to guarantee that, when passing through the channel, each ion can effectively interact with any binding sites on the channel wall. Therefore, it remains a long-sought goal to develop artificial channels with angstrom-scaled dimensions similar to the size of halogen ions ${ }^{14}$.

Metal-organic frameworks (MOFs), an emerging family of porous crystalline materials, have high porosity, large surface area and uniform pore size, making them of great interest for gas storage $^{15,16}$, capture ${ }^{17,18}$ and separation technologies ${ }^{19-23}$. In particular, water-stable MOFs that have angstrom-scaled pore windows have recently proven to be promising for water processing ${ }^{24}$. For instance, zeolitic imidazolate framework-8 (ZIF-8) contains $3.4 \AA$ pore windows and has been theoretically predicted to be a potential reverse osmosis membrane material for water purification $^{25}$. Subsequently, Huang et al. have experimentally demonstrated that ZIF-8 membranes can be used for seawater desalination via ionic sieving, achieving an ion rejection value of more than $99.8 \%{ }^{26}$. Recently, zirconium based UiO-66 membranes with channels comprised of octahedral and tetrahedral cavities $(\sim 11 \AA$ and $\sim 9 \AA$, respectively) connected by $\sim 6 \AA$ pore windows $^{27,28}$ have been fabricated by Li et al. These membranes achieve high rejection of multivalent metal ions that have hydrated ionic diameters $(\sim 7.0-9.0 \AA)$ larger than the MOF window size $\mathrm{e}^{29}$. MOF particles with tailored functionalities have been shown to be efficient molecular and ionic adsorbents owing to specific interactions between the molecules/ions of interest and MOF active sites ${ }^{30-33}$. For example, arsenic ions have been removed from water by using $\mathrm{UiO}-66$ crystals as adsorbents through the hydroxyl and benzenedicarboxylate binding sites ${ }^{31}$. Furthermore, a series of MOFs (i.e., MIL-53(Fe), MIL-53(Cr), CAU-6, UiO-66(Zr), UiO-66(Hf), ZIF-7, ZIF-8 and ZIF-9) has been explored as potential adsorbents for removing fluoride from water ${ }^{34}$. Based on these studies, $\mathrm{UiO}-66(\mathrm{Zr})$ derivative MOFs display the highest $\mathrm{F}^{-}$adsorption capacity due to the specific binding of $\mathrm{F}^{-}$through the hydroxyl and open zirconium sites $^{35,36}$. Therefore, we hypothesize that UiO-66 MOFs having channels with angstrom-sized pore windows and specific
$\mathrm{F}^{-}$binding sites might be suitable candidates for constructing ion channels that offer highly selective and rapid transport of $\mathrm{F}^{-}$ions.

Herein, we report ultrahigh fluoride ion conductive and selective MOF channels with sub-1-nanometer windows and a variety of functional groups constructed by in-situ growth of zirconiumbased UiO-66-X $\left(\mathrm{X}=\mathrm{H}, \mathrm{NH}_{2}\right.$, and $\left.\mathrm{N}^{+}\left(\mathrm{CH}_{3}\right)_{3}\right)$ MOFs into polyethylene terephthalate (PET) nanochannels (Fig. 1b). The UiO-66$\mathrm{X}$ MOF channels, which consist of angstrom-sized windows and nanometer-sized cavities with positive framework charges ${ }^{37}$, function as fluoride ion channels, exhibiting ultrahigh $\mathrm{F}^{-}$conductivity and selectivity over other anions $\left(\mathrm{F}^{-} \gg \mathrm{Cl}^{-}>\mathrm{Br}^{-}>\mathrm{I}^{-}>\right.$ $\left.\mathrm{NO}_{3}{ }^{-}>\mathrm{SO}_{4}{ }^{2-}\right)$. The selectivity increases with increasing dehydrated anion diameter and can be tuned by varying the functional groups on MOFs. For instance, PET-UiO-66- $\mathrm{N}^{+}\left(\mathrm{CH}_{3}\right)_{3}$ nanochannels have $\mathrm{F}^{-} / \mathrm{Cl}^{-}$selectivity values up to $\sim 240$, rivaling those of many biological $\mathrm{F}^{-}$ion channels ${ }^{7,9}$. Based on a combination of molecular dynamics simulations and experiments, we can attribute the high $\mathrm{F}^{-} / \mathrm{Cl}^{-}$selectivity in UiO-66-X channels mainly to the high concentration of $\mathrm{F}^{-}$ions in the sub-nanometer-sized MOF channels that arises from the strong binding between $\mathrm{F}^{-}$ions and $\mathrm{F}^{-}$specific binding sites in $\mathrm{UiO}-66-\mathrm{X}$ frameworks.

\section{Results}

Fabrication of sub-1-nanometer porous MOF channels. Sub-1nanometer MOF channels were fabricated by in-situ growth of UiO-66-X crystals into $12-\mu \mathrm{m}$-thick single-nanochannel PET membranes (see Methods for more details). Single bullet-shaped nanochannels embedded within a PET membrane (Fig. 2a) were fabricated by a surfactant-protected ion-track-etching method ${ }^{38}$. Scanning electron microscopy (SEM) images of the tip, tip cross section and base of the PET-nanochannel displayed a bullet-like nanochannel (Fig. 2a). The mean nanochannel tip diameter was $36.3 \pm 5.6 \mathrm{~nm}$, and the mean nanochannel base diameter was $328.3 \pm 35.2 \mathrm{~nm}$ (Supplementary Fig. 1). Here, the bullet-shaped single-nanochannel PET membranes were prepared as supports to house MOFs in the nanochannels, since the asymmetric shape and the benzene-1,4-dicarboxylic acid (BDC)-linkers on the PETnanochannel wall favor in-situ growth of UiO-66-X MOFs inside the nanochannels (Fig. 2a).

Following in-situ growth of UiO-66-X, the PET nanochannel was completely filled with UiO-66-X MOF crystals (Fig. 2b), which was verified by SEM images of the tip, tip cross section, and base of the PET-UiO-66-X nanochannel (Fig. 2b), as well as energy dispersive X-ray spectroscopy (EDX) mapping of the PETnanochannel membrane before and after UiO-66-X growth (Supplementary Fig. 2a-d). The powder X-ray diffraction (XRD) patterns and X-ray photoelectron spectroscopy (XPS) spectra of PET and PET-UiO-66-X nanochannels confirmed the existence of UiO-66-X crystals in the PET nanochannels (Supplementary Fig. 2e, f). Based on $\mathrm{N}_{2}$ adsorption/desorption isotherm profiles, UiO-66-X crystals had Brunauer-Emmett-Teller (BET) surface areas of $1372 \pm 8 \mathrm{~m}^{2} \mathrm{~g}^{-1}, 1133 \pm 11 \mathrm{~m}^{2} \mathrm{~g}^{-1}$ and $947 \pm 13 \mathrm{~m}^{2} \mathrm{~g}^{-1}$ for $\mathrm{UiO}-66, \mathrm{UiO}-66-\mathrm{NH}_{2}$, and $\mathrm{UiO}-66-\mathrm{N}^{+}\left(\mathrm{CH}_{3}\right)_{3}$, respectively (Fig. 2c), calculated according to the four BET consistency criterion $^{39,40}$. The pore size distributions revealed nanometersized cavities with $\sim 6 \AA$ window diameters and a gradual decrease in window size going from $\mathrm{UiO}-66$, to $\mathrm{UiO}-66-\mathrm{NH}_{2}$, and to $\mathrm{UiO}-$ $66-\mathrm{N}^{+}\left(\mathrm{CH}_{3}\right)_{3}$, consistent with the increase in MOF functional group size (Fig. 2d). These results were further confirmed by the window and cavity sizes of UiO-66-X channels calculated via Zeo ++ (see Supplementary Fig. 3 for more details).

Ultrahigh $\mathrm{F}^{-}$conductivity and selectivity in MOF channels. To investigate ion conduction in UiO-66-X filled PET nanochannels (PET-UiO-66-X), current-voltage $(I-V)$ curves of a 

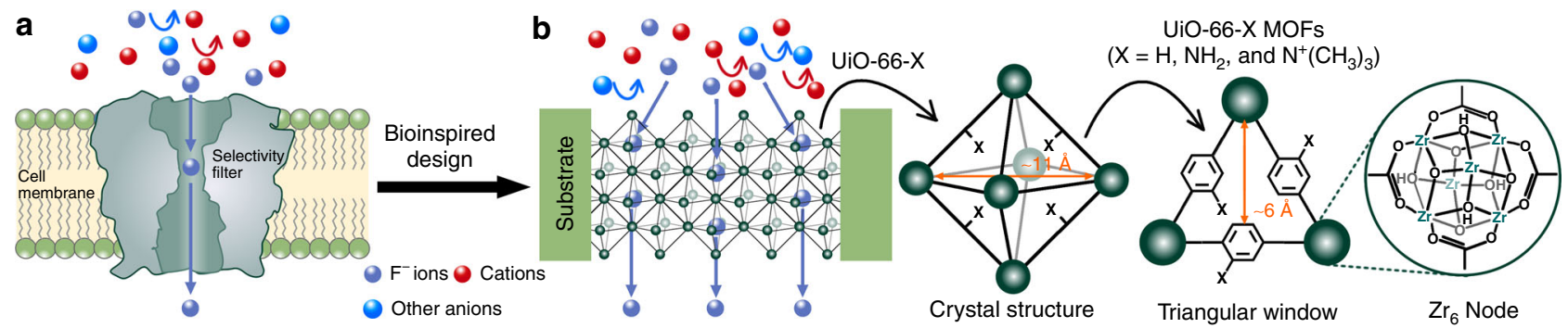

Fig. 1 Bioinspired design of synthetic MOF channels for fluoride ion conduction. a Schematic of a biological fluoride $\left(F^{-}\right)$ion channel with an angstromsized region as $\mathrm{F}^{-}$selectivity filter and nanometer-sized vestibule and outlet for selective, ultrafast $\mathrm{F}^{-}$transport. $\mathbf{b}$ Schematics of bioinspired artificial zirconium-based UiO-66-X ( $\mathrm{X}=\mathrm{H}_{1} \mathrm{NH}_{2}$, and $\left.\mathrm{N}^{+}\left(\mathrm{CH}_{3}\right)_{3}\right)$ MOF channels with sub-1-nanometer crystalline pores for selective and ultrafast $\mathrm{F}^{-}$transport. Sub-1-nanometer MOF channels consist of angstrom-sized triangular windows ( $6 \AA$ in diameter) for ion sieving and nanometer-sized octahedral cavities $(\sim 11 \AA$ in diameter) for ultrafast ion conduction
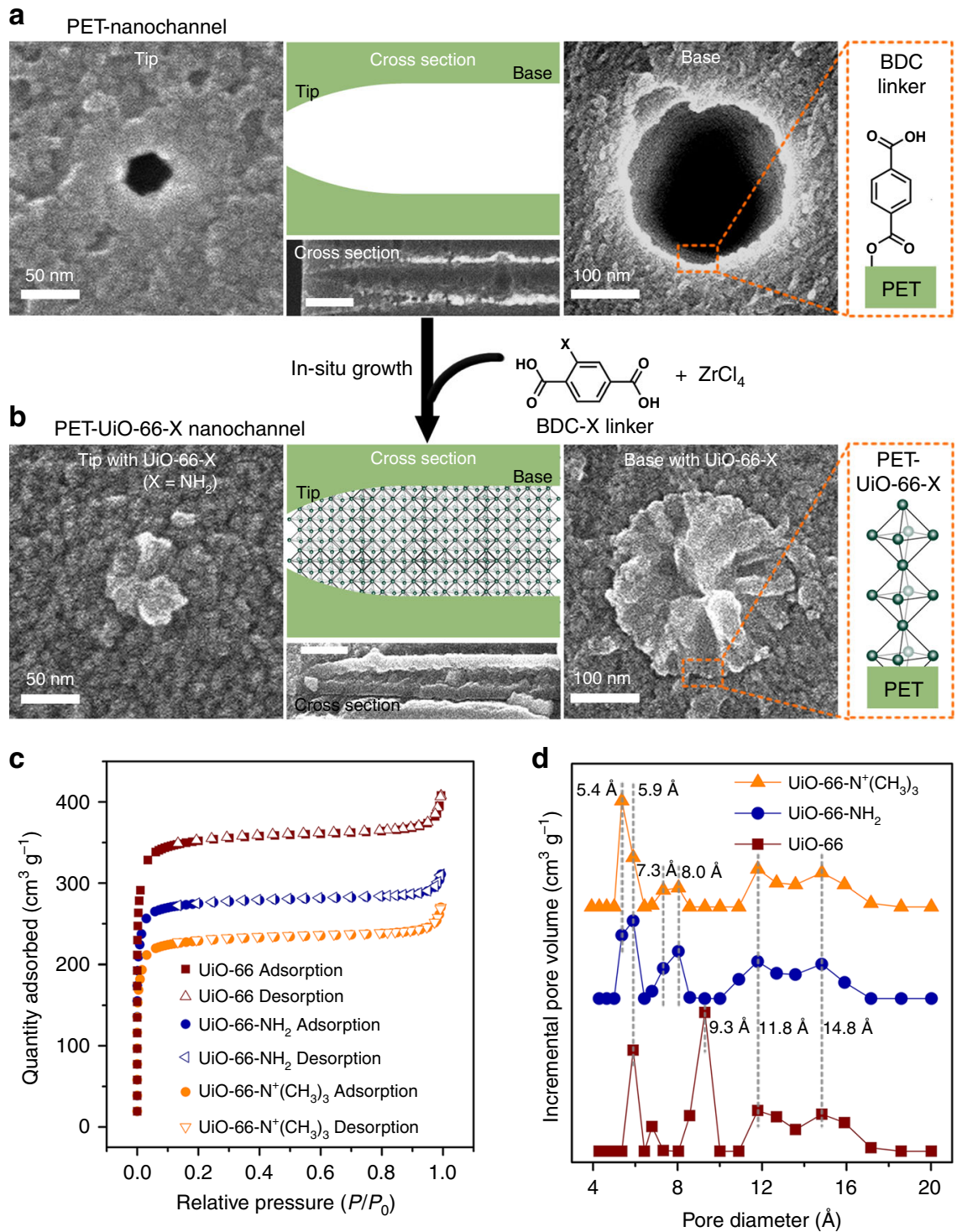

Fig. 2 Fabrication and characterization of PET-UiO-66-X nanochannels. a Schematic of a single bullet-shaped nanochannel and SEM images of the channel tip, cross section (the scale bar is $500 \mathrm{~nm}$ ) and base. Average tip diameter is $36.3 \pm 5.6 \mathrm{~nm}$, while average base diameter is $328.3 \pm 35.2 \mathrm{~nm}$. The PET nanochannel surface possesses BDC linkers for in-situ growth of UiO-66-X MOFs. b Schematic of a PET-UiO-66-X nanochannel and SEM images of the nanochannel tip, cross section (the scale bar is $500 \mathrm{~nm}$ ) and base (SEM images of PET-UiO-66- $\mathrm{NH}_{2}$ are shown as an example). Schematic of UiO-66-X crystal structure along the PET-nanochannel surface. $\mathbf{c} \mathrm{N}_{2}$ adsorption/desorption isotherms of UiO-66, UiO-66- $\mathrm{NH}_{2}$, and $\mathrm{UiO}-66-\mathrm{N}^{+}\left(\mathrm{CH}_{3}\right)_{3}$. $\mathbf{d}$ Pore size distributions of UiO-66-X MOFs. The distributions for UiO-66- $\mathrm{NH}_{2}$ and $\mathrm{UiO}-66-\mathrm{N}^{+}\left(\mathrm{CH}_{3}\right)_{3}$ are displayed vertically for ease of viewing. Pore size decreases as MOFs functional group size increases 

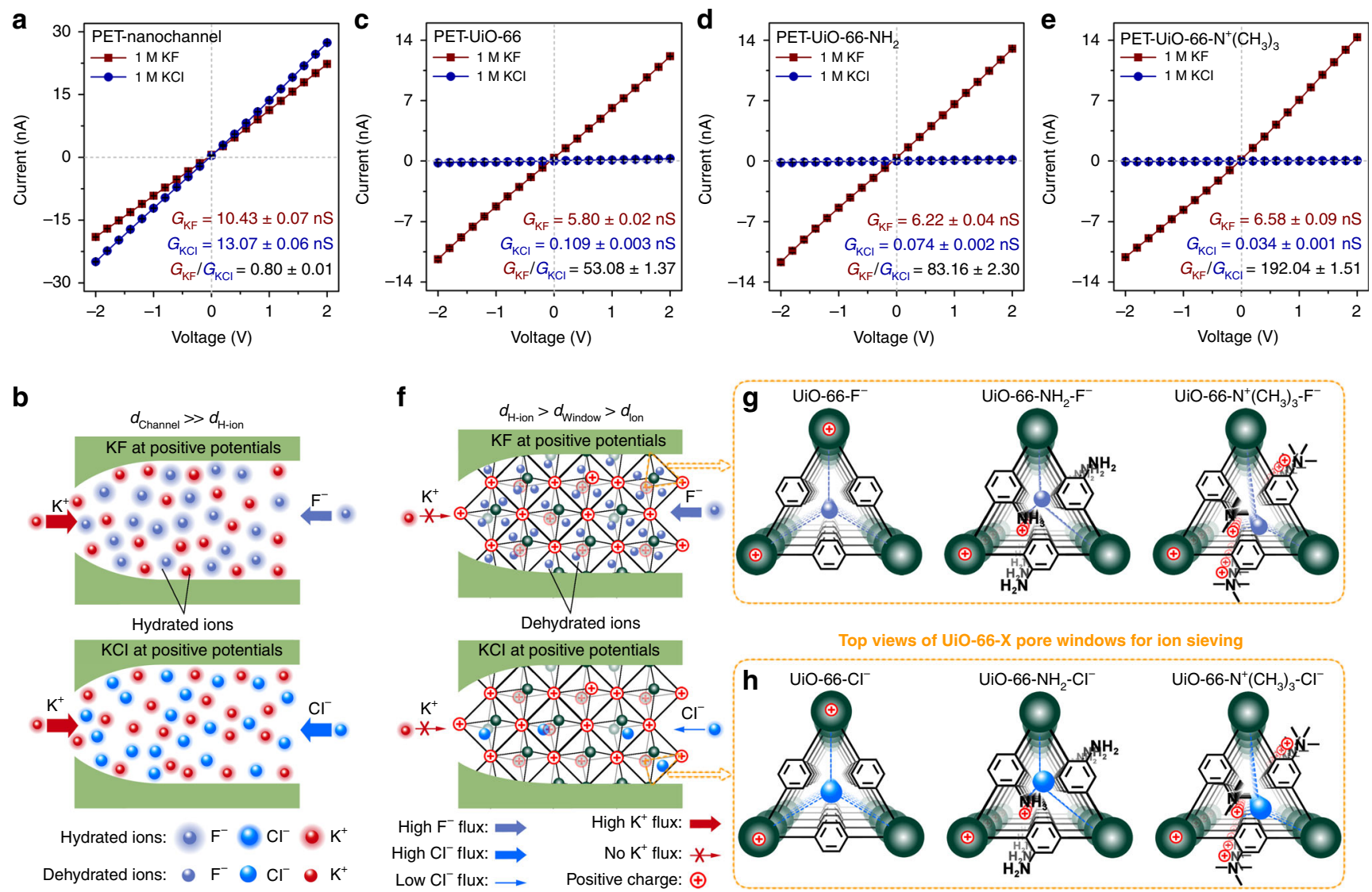

Fig. 3 Ionic transport properties of PET nanochannels and sub-1-nanometer MOF channels. a Symmetric I-V curves of a bullet-shaped PET-nanochannel observed in $1.0 \mathrm{M} \mathrm{KF}$ and $\mathrm{KCl}$ solutions, respectively. $\mathbf{b}$ Schematics of hydrated ions transport in a PET-nanochannel. Because $d_{\text {Channel }} \gg d_{\mathrm{H} \text {-ion, }}$ ions are hydrated in the PET-nanochannel. The diameter of hydrated $\mathrm{F}^{-}$is larger than that of hydrated $\mathrm{Cl}^{-}$, so hydrated $\mathrm{F}^{-}$ions conduct slower than hydrated $\mathrm{Cl}^{-}$ ions in the PET-nanochannel. c-e I-V curves of PET-UiO-66-X nanochannels measured in $1.0 \mathrm{M} \mathrm{KF}$ and KCl solutions, respectively. Compared with UiO-66 and $\mathrm{UiO}-66-\mathrm{NH}_{2}$ channels, $\mathrm{UiO}-66-\mathrm{N}^{+}\left(\mathrm{CH}_{3}\right)_{3}$ channels exhibit the highest $\mathrm{F}^{-}$conductance and selectivity. Error bars represent the standard deviation of three measurements of a sample. $\mathbf{f}$ Schematic illustrations of dehydrated ions passing through sub-1-nanometer PET-UiO-66-X nanochannels. Ions are dehydrated in MOF channels because $d_{\mathrm{H} \text {-ion }}>d_{\text {Window }}>d_{\text {lon. }}$. The angstrom-sized MOF pore windows with specific $\mathrm{F}^{-}$binding zirconium sites and functional $\mathrm{NH}_{2}$ and $\mathrm{N}^{+}\left(\mathrm{CH}_{3}\right)_{3}$ groups serve as $\mathrm{F}^{-}$selectivity filter for ion sieving, so dehydrated $\mathrm{F}^{-}$ions conduct faster than $\mathrm{Cl}^{-}$in $\mathrm{PET}-\mathrm{UiO}-66-\mathrm{X}$ nanochannels. $\mathbf{g}$, $\mathbf{h}$ Top view of UiO-66-X pore windows. UiO-66- $\mathrm{N}^{+}\left(\mathrm{CH}_{3}\right)_{3}$ channels have the smallest window size and strongest $\mathrm{F}^{-}$specific interactions due to the $\mathrm{N}^{+}\left(\mathrm{CH}_{3}\right)_{3}$ groups compared with $\mathrm{UiO}-66$ and $\mathrm{UiO}-66-\mathrm{NH}_{2}$ channels

PET-nanochannel before and after UiO-66-X growth were measured in $1.0 \mathrm{M} \mathrm{KF}$ and $\mathrm{KCl}$ aqueous solutions (see Supplementary Fig. 4a, b for the testing apparatus). For pristine bullet-shaped PET-nanochannels (i.e., with no MOFs in the nanochannels), symmetric $I-V$ curves were observed in both $\mathrm{KCl}$ and $\mathrm{KF}$ solutions (Fig. 3a). In the pristine PET nanochannels, the absolute values of $\mathrm{KCl}$ currents were slightly higher than those of $\mathrm{KF}$, consistent with the slightly smaller diameter of hydrated $\mathrm{Cl}^{-}$ relative to $\mathrm{F}^{-}$(i.e., $\mathrm{F}^{-}(7.04 \AA)>\mathrm{Cl}^{-}(6.64 \AA)^{41}$, Supplementary Table 1). Since the two electrolyte solutions share the same cation (i.e., $\mathrm{K}^{+}$), differences in PET-nanochannel conductance are ascribed to the anions (i.e., $\mathrm{F}^{-}$and $\mathrm{Cl}^{-}$). In the PET-nanochannel, because $d_{\text {Channel }}$ (channel diameter) is much larger than $d_{\mathrm{H}-\text { ion }}$ (hydrated ionic diameter), ions should be hydrated, and both cations and anions pass through the PET-nanochannel (Fig. 3b). Based on PET-nanochannel conductance values $(G)$ calculated from the slopes of the PET-nanochannel $I-V$ curves, $G_{\mathrm{KF}}$ and $G_{\mathrm{KCl}}$ were $10.43 \pm 0.07 \mathrm{nS}$ and $13.07 \pm 0.06 \mathrm{nS}$, respectively. That is, without MOFs, the PET nanochannels exhibit very limited anionic selectivity on the basis of the conductance ratio value (i.e., $G_{\mathrm{KF}} / G_{\mathrm{KCl}}$ ) of $0.80 \pm 0.01$.

After PET nanochannels were filled with UiO-66-X, absolute values of KF flux (i.e., current) at a given voltage were somewhat smaller than those in the pristine PET-nanochannel, but $\mathrm{KCl}$ current values were reduced by more than 100 -fold at a given voltage relative to $\mathrm{KCl}$ current values in the pristine PETnanochannel (Fig. 3c-e). $G_{\mathrm{KF}}$ values of PET-UiO-66, PET-UiO$66-\mathrm{NH}_{2}$, and PET-UiO-66- $\mathrm{N}^{+}\left(\mathrm{CH}_{3}\right)_{3}$ nanochannels were $5.80 \pm$ $0.02 \mathrm{nS}, 6.22 \pm 0.04 \mathrm{nS}$, and $6.58 \pm 0.09 \mathrm{nS}$, respectively. In sharp contrast, $G_{\mathrm{KCl}}$ values of the PET-UiO-66, PET-UiO-66- $\mathrm{NH}_{2}$, and PET-UiO-66-N ${ }^{+}\left(\mathrm{CH}_{3}\right)_{3}$ nanochannels were only $0.109 \pm 0.003$, $0.074 \pm 0.002$, and $0.034 \pm 0.001 \mathrm{nS}$, respectively. Consequently, the PET-MOF nanochannels exhibit ultrahigh $G_{\mathrm{KF}} / G_{\mathrm{KCl}}$ selectivity, varying from $53.08 \pm 1.37$ to $192.04 \pm 1.51$, which are much higher values than those of PET nanochannels (Supplementary Fig. $4 \mathrm{c}-\mathrm{f}$ ). The ultrahigh selectivity of these PET-MOF nanochannels is ascribed to the unique structure and chemical properties of sub-1-nanometer UiO-66-X channels.

PET-UiO-66-X nanochannels are positively charged in neutral water, and $\mathrm{UiO}-66-\mathrm{N}^{+}\left(\mathrm{CH}_{3}\right)_{3}$ has the highest positive charge density on MOF crystals, as indicated by zeta potential in Supplementary Table 2 . UiO-66 and $\mathrm{UiO}-66-\mathrm{NH}_{2}$ are positively charged because the $\mathrm{Zr}-\mathrm{OH}$ on the $\mathrm{Zr}_{6}$ node tends to form $\mathrm{Zr}-\mathrm{OH}_{2}{ }^{+}$in aqueous solution when the $\mathrm{pH}$ value is below $8.3^{42}$, while the amino group of $\mathrm{UiO}-66-\mathrm{NH}_{2}$ can be protonated when the solution $\mathrm{pH}$ value is below 5 , and $\mathrm{UiO}-66-\mathrm{N}^{+}\left(\mathrm{CH}_{3}\right)_{3}$ is 
positively charged mainly because of its quaternary ammonium groups (cf. Supplementary Fig. 5). Accordingly, the highly positively charged sub-1-nanometer MOF channels preferentially transport anions via electrostatic attraction and exclude cations (e.g., $\mathrm{K}^{+}$) via electrostatic repulsion, and XPS spectra of KF- and KCl-treated UiO-66-X crystals showed that $\mathrm{F}^{-}$concentrations were much higher than $\mathrm{Cl}^{-}$concentrations in UiO-66-X channels because additional $\mathrm{F}^{-}$ions can be adsorbed into UiO-66-X channels by $\mathrm{Zr}$ sites through specific $\mathrm{Zr}-\mathrm{F}$ interactions, while $\mathrm{Cl}^{-}$ ions cannot (Supplementary Tables 3-5 and Supplementary Fig. 6a-d). The exclusion of cations was confirmed by XPS spectra of KF- and KCl-treated UiO-66-X crystals. No detectable peaks associated with $\mathrm{K} 2 \mathrm{p}$ or $\mathrm{K} 2 \mathrm{~s}$ were observed in the XPS spectra at low ion concentrations $(<0.5 \mathrm{M})$, while $K 2$ p peaks were observed in the XPS spectra at high KF concentrations $(\geq 0.5 \mathrm{M})$ (Supplementary Tables 3-5). To determine the concentration of $\mathrm{K}^{+}$ions in MOF channels at low external ion concentrations, we used inductively coupled plasma optical emission spectrometry to measure the ion concentration changes of bulk $0.01 \mathrm{M}$ $\mathrm{KCl}$ and $\mathrm{KF}$ solutions before and after exposure to UiO-66 crystals. $0.1 \mathrm{~g} \mathrm{UiO}-66$ crystals adsorbed $\sim 0.192 \mathrm{mmol} \mathrm{F}^{-}$ions and $\sim 0.019 \mathrm{mmol} \mathrm{K}^{+}$from $0.01 \mathrm{M} \mathrm{KF}$ solution, and the ratio of $\mathrm{F}^{-} / \mathrm{K}^{+}$in UiO-66 channel was $\sim 10$ (Supplementary Fig. 6e). In contrast, a negligible $\mathrm{K}^{+}$adsorption capacity of $\sim 0.016 \mathrm{mmol} \mathrm{g}^{-1}$ was observed in $0.01 \mathrm{M} \mathrm{KCl}$ solution (Supplementary Fig. 6f). These results unambiguously confirmed that only a small amount of $\mathrm{K}^{+}$ions was present in the UiO-66-X MOF channels. Therefore, the ion conductance of PET-MOF nanochannels is derived mainly from the movement of anions $\left(G \approx G_{-}\right.$, i.e., $G_{K F} \approx G_{F^{-}}$, , while the ion conductance of a pristine PETnanochannel, containing no MOFs, is due to the movement of both cations and anions $\left(G=G_{+}+G_{-}\right.$, i.e., $\left.G_{K F}=G_{K^{+}}+G_{F^{-}}\right)$.

To further demonstrate the anion selectivity of PET-MOF nanochannels, anion conductivities $(\kappa)$ of PET and PETMOF nanochannels were calculated (see Methods for details). Experimental $\kappa_{K F}$ and $\kappa_{K C l}$ values for $1.0 \mathrm{M}$ bulk solutions were $8.531 \mathrm{~S} \mathrm{~m}^{-1}$ and $10.820 \mathrm{~S} \mathrm{~m}^{-1}$, respectively. Pristine PET-nanochannels exhibited conductivities similar to those in bulk solution (Supplementary Fig. 7a). For bulk solutions, $\kappa=10^{3}\left(\mu_{+}+\mu_{-}\right) \times c \times F$, where $\mu$ is the ion mobility ${ }^{43}$ (Supplementary Table 1$), c$ is the salt concentration, and $F$ is Faraday's constant. Based upon this formula, the anion conductivity in bulk solution can be calculated as $\kappa_{-}=\kappa_{E x p} \mu_{-} /\left(\mu_{+}+\mu_{-}\right)$, where $\kappa_{\text {Exp }}$ is the experimental conductivity value of the electrolyte solution. Accordingly, $1.0 \mathrm{M}$ bulk $\kappa_{F^{-}}$and $\kappa_{\mathrm{Cl}^{-}}$values were calculated to be $3.650 \mathrm{~S} \mathrm{~m}^{-1}$ and $5.511 \mathrm{~S} \mathrm{~m}^{-1}$, respectively. Similarly, $\kappa_{\mathrm{F}^{-}}$and $\kappa_{\mathrm{Cl}^{-}}$values of pristine PET-nanochannels were $3.810 \pm 0.025 \mathrm{~S}$ and $5.680 \pm 0.027 \mathrm{~S} \mathrm{~m}^{-1}$, respectively. For PET-MOF channels, based on the assumption that all conductivity is attributed to the anion, $\kappa_{-} \approx \kappa_{\text {Exp }}$. $\kappa_{\mathrm{F}^{-}}$of UiO-66, UiO-66- $\mathrm{NH}_{2}$, and UiO-66$\mathrm{N}^{+}\left(\mathrm{CH}_{3}\right)_{3}$ filled PET nanochannels were $6.969 \pm 0.030,9.169 \pm$ 0.060 , and $10.420 \pm 0.142 \mathrm{~S} \mathrm{~m}^{-1}$, respectively. Interestingly, these values are considerably higher than the fluoride conductivity in bulk solution (i.e., $3.650 \mathrm{~S} \mathrm{~m}^{-1}$ ). Values of $\kappa_{\mathrm{Cl}^{-}}$for $\mathrm{UiO}-66$, $\mathrm{UiO}-66-\mathrm{NH}_{2}$, and UiO-66- ${ }^{+}\left(\mathrm{CH}_{3}\right)_{3}$ filled PET nanochannels were $0.131 \pm 0.004, \quad 0.110 \pm 0.004$, and $0.054 \pm 0.001 \mathrm{~S} \mathrm{~m}^{-1}$, respectively (Supplementary Fig. $7 \mathrm{~b}$ ). These values are far below the chloride conductivity in bulk solution $\left(5.511 \mathrm{~S} \mathrm{~m}^{-1}\right)$. Based on these results, PET-UiO-66-X nanochannels exhibit much higher $\mathrm{F}^{-}$conductivity than that measured in bulk solution or a pristine PET-nanochannel, and PET-UiO-66-N ${ }^{+}\left(\mathrm{CH}_{3}\right)_{3}$ nanochannels have the highest $\mathrm{F}^{-}$conductivity and $\mathrm{F}^{-} / \mathrm{Cl}^{-}$ selectivity among the MOFs considered.

The pore windows of UiO-66-X crystals are approximately $6.0 \AA$ in diameter (Fig. 2d). The diameters of the hydrated anions considered in this study are all greater than $6.0 \AA$ (Supplementary Table 1). However, the diameters of the dehydrated anions are less than $6.0 \AA$ (Supplementary Table 1$)$. That is, $d_{\mathrm{H}-\text { ion }}>d_{\text {Window }}>d_{\text {Ion }}$, where $d_{\text {Ion }}$ is the dehydrated ion diameter, so any anions transported through MOF-filled PET nanochannels must be at least partially dehydrated to permeate through the pore windows of PET-UiO-66-X nanochannels (Fig. $3 \mathrm{f}-\mathrm{h}$ ). In addition to the dehydration effect, the sub-1-nanometer MOF channels possess a specific binding affinity for $\mathrm{F}^{-}$over $\mathrm{Cl}^{-}$due to the zirconium sites on the $\mathrm{Zr}$-nodes and positively charged amino and quaternary ammonium groups ${ }^{34,35}$ (Supplementary Fig. 6a-c). This selective affinity also contributes to the ultraselective $\mathrm{F}^{-}$ transport in MOF channels. Moreover, the $\mathrm{F}^{-}$conductivity increases slightly, while $\mathrm{Cl}^{-}$conductivity decreases noticeably with an increase in the size of functional group in MOF channels (i.e., from UiO-66, to $\mathrm{UiO}-66-\mathrm{NH}_{2}$, and to $\left.\mathrm{UiO}-66-\mathrm{N}^{+}\left(\mathrm{CH}_{3}\right)_{3}\right)$, resulting in the increasing of $\mathrm{F}^{-} / \mathrm{Cl}^{-}$selectivity (Fig. $3 \mathrm{c}-\mathrm{e}$ ). Going from $\mathrm{UiO}-66$, to $\mathrm{UiO}-66-\mathrm{NH}_{2}$, and to $\mathrm{UiO}-66-\mathrm{N}^{+}\left(\mathrm{CH}_{3}\right)_{3} \mathrm{MOF}$ is accompanied by a gradual decrease in window size, and the smaller the aperture size, the lower is the conductivity of anions, such as $\mathrm{Cl}^{-}$, through the MOF channels. In addition, interactions between functional MOFs and $\mathrm{F}^{-}$ions may influence the selectivity. For example, quaternary $\mathrm{UiO}-66-\mathrm{NH}_{2}$ (UiO-66$\left.\mathrm{N}^{+}\left(\mathrm{CH}_{3}\right)_{3}\right)$, which has the most positive charge density, exhibits stronger electrostatic interaction with $\mathrm{F}^{-}$than $\mathrm{UiO}-66-\mathrm{NH}_{2}$ and $\mathrm{UiO}-66$ do. These interactions lead to more $\mathrm{F}^{-}$ions entering the UiO-66- $\mathrm{N}^{+}\left(\mathrm{CH}_{3}\right)_{3}$ channels (Supplementary Fig. 6a-c), a conclusion deduced from the zeta potential values of UiO-66-X after being loaded with $\mathrm{F}^{-}$ions, where $\mathrm{UiO}-66-\mathrm{N}^{+}\left(\mathrm{CH}_{3}\right)_{3}$ has the most negative zeta potential value (Supplementary Table 2). Consequently, the PET-UiO-66-N ${ }^{+}\left(\mathrm{CH}_{3}\right)_{3}$ nanochannels exhibit the highest $\mathrm{F}^{-} / \mathrm{Cl}^{-}$selectivity, upto 192 , making them even more selective than most biological and synthetic fluoride ion channels (Supplementary Tables 6, 7). Therefore, specific interactions between $\mathrm{F}^{-}$ions and the functional groups/sites on MOF frameworks may well be essential for the observed ultraselectivity of PET-MOF nanochannels.

$\mathrm{F}^{-} / \mathrm{Cl}^{-}$selectivity mechanisms in MOF channels. To gain a deeper understanding of the observed ultrahigh $\mathrm{F}^{-} / \mathrm{Cl}^{-}$selectivity in UiO-66-X channels, we performed molecular dynamics (MD) simulations. The ions transport of $\mathrm{KF}$ and $\mathrm{KCl}$ in $\mathrm{UiO}-66$ channels under an external electric field was simulated as an example. Figure 4a depicts the molecular system of our MD simulations (See more details in Methods).

The ion conductivity in MOF channels depends on ion concentration and mobility. We initially investigated $\mathrm{F}^{-}$and $\mathrm{Cl}^{-}$ion mobility in UiO-66 channels to determine whether ions might exhibit anomalous transport behavior in sub-nanometersized UiO-66, owing to the sub-nano-confinement effect and specific ion-surface interactions ${ }^{44}$. To simulate a dilute concentration of $\mathrm{Cl}^{-}$in UiO-66 in our experiments, one pair of $\mathrm{K}^{+}$and $\mathrm{Cl}^{-}$ ions was placed in a $2 \times 2 \times 2$ supercell, corresponding to a concentration of $0.0457 \mathrm{M}$. For comparison, similar MD simulations were performed for $\mathrm{F}^{-}$ions. Figure $4 \mathrm{~b}$ and Supplementary Table 8 show mobility results. The $\mathrm{Cl}^{-}$ion has a mobility of 0.058 $\pm 0.013 \times 10^{-4} \mathrm{~cm}^{2} \mathrm{~V}^{-1} \mathrm{~s}^{-1}$, whereas the $\mathrm{F}^{-}$ion has a much lower mobility, $0.0015 \pm 0.001 \times 10^{-4} \mathrm{~cm}^{2} \mathrm{~V}^{-1} \mathrm{~s}^{-1}$. These results are reasonably close to the mobilities estimated by using the umbrella sampling method and transition state theory ${ }^{45,46}$ (see details in Methods, Supplementary Fig. 8, and Supplementary Fig. 9). Figure $4 c-e$ depict the radial distribution function (RDF), $g(r)$, of water molecules around the anions in the center of the large octahedral cavity and the pore window, respectively. Compared with $\mathrm{F}^{-}$, the second hydration shell of $\mathrm{Cl}^{-}$appears much weaker, 
a

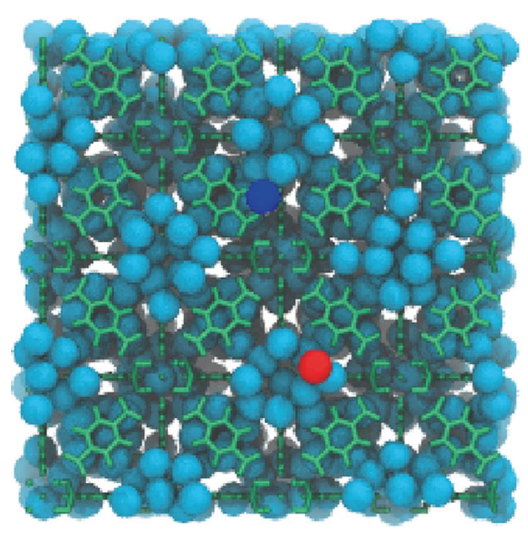

C

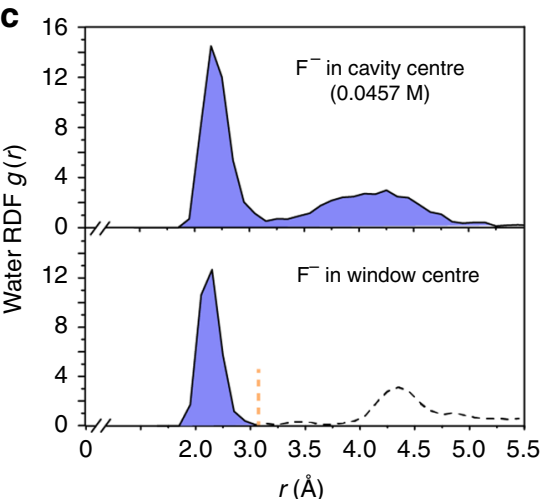

e
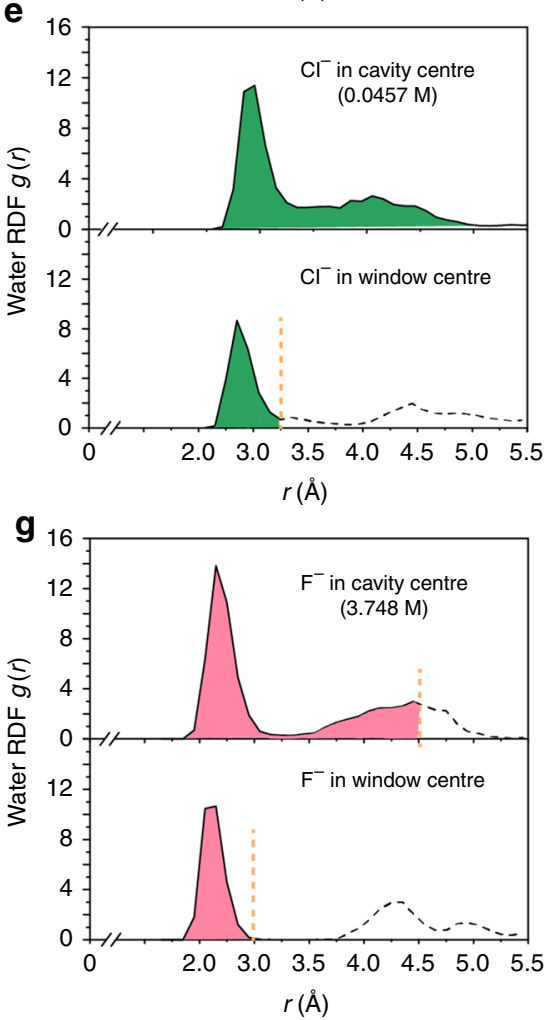

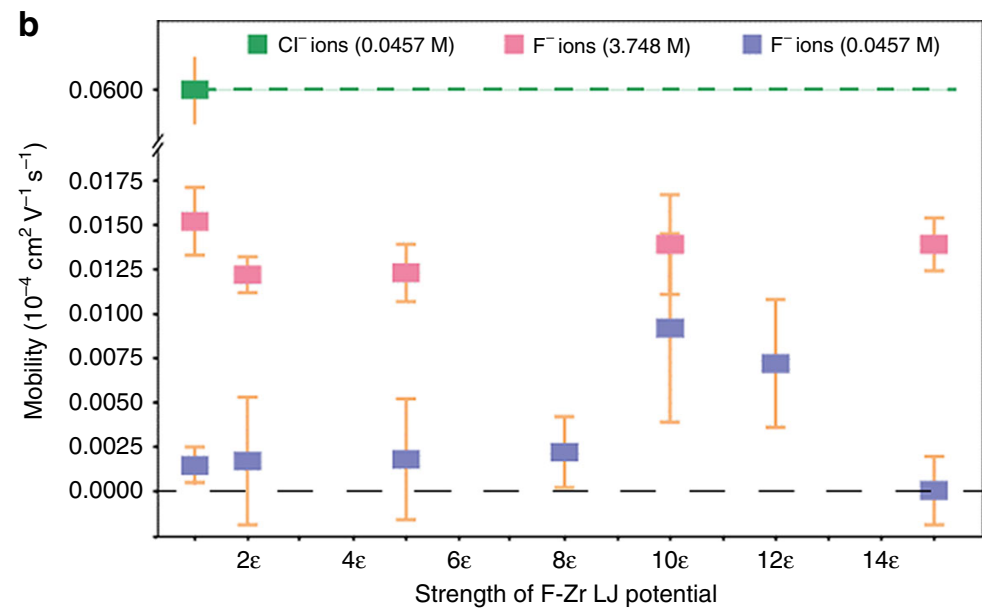

d

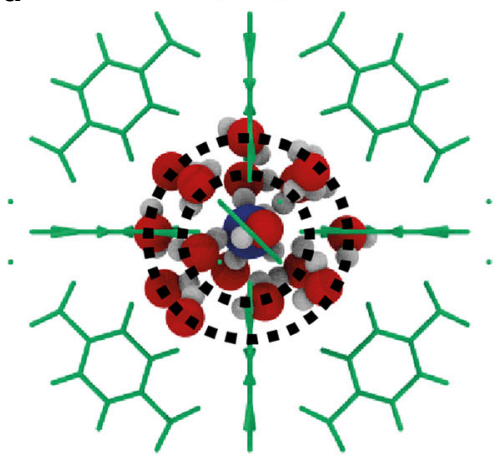

f

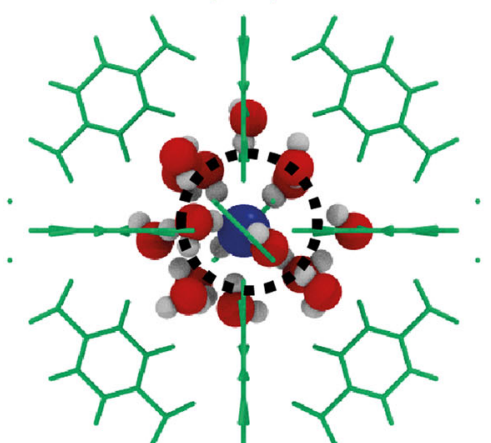

$\mathbf{h}$

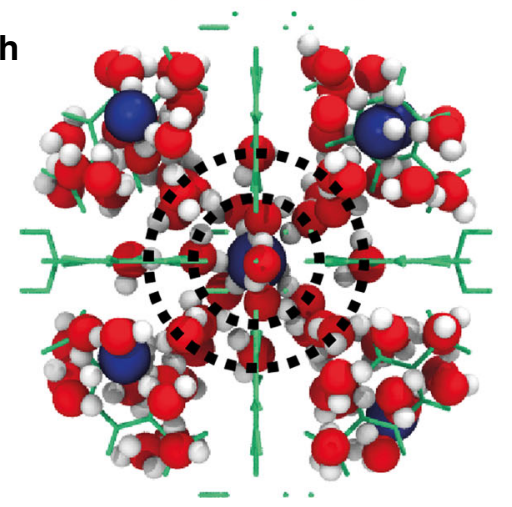

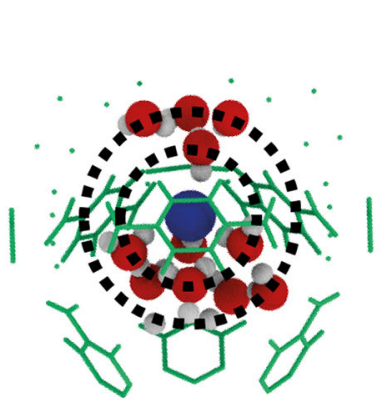
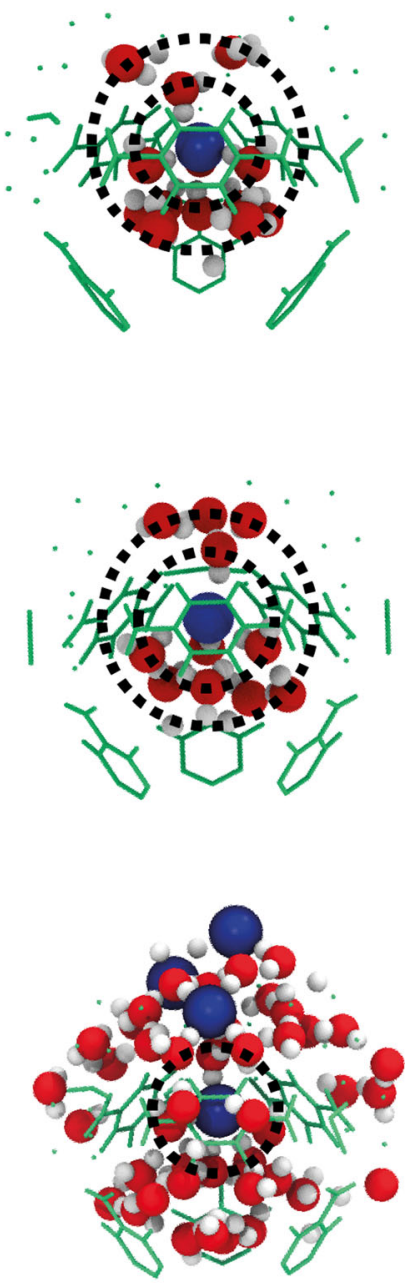

which is confirmed in the molecular cartoons in Fig. $4 \mathrm{~d}-\mathrm{f}$. The cartoons also indicate that the second hydration shell is removed for anions passing through the window (i.e., the sieving mechanism). Owing to the tightly bonded second shell in the octahedral cavity (Fig. 4d), a higher dehydration energy should be required for $\mathrm{F}^{-}$ions to transport through the small windows, leading to much smaller mobility for $\mathrm{F}^{-}$than for $\mathrm{Cl}^{-}$(Fig. $4 \mathrm{~b}$ ). However, this result is precisely opposite to the observed high $\mathrm{F}^{-}$ conductivity in our experiments, confirming the indispensable role of ion concentration on the measured high $\mathrm{F}^{-} / \mathrm{Cl}^{-}$selectivity. 
Fig. 4 MD simulations of ion transport in UiO-66 channels. a The simulation cartoon shows UiO-66 cavities filled with water molecules (sky blue spheres), and they are connected via narrow windows. For clarity, UiO-66 is shown as a green wireframe. $\mathrm{K}^{+}$and $\mathrm{F}^{-}$ions are represented by red and dark blue spheres, respectively. $\mathbf{b}$ The mobility of $\mathrm{Cl}^{-}$and $\mathrm{F}^{-}$ions in UiO-66. $\mathrm{F}^{-}$mobility is presented as a function of the strength of $\mathrm{F}-\mathrm{Zr} \mathrm{LJ}$ potential at $0.0457 \mathrm{M}$ and $3.748 \mathrm{M}$, respectively. At $3.748 \mathrm{M}, \mathrm{F}^{-}$mobility is enhanced by around 10 times compared with that at $0.0457 \mathrm{M}$. Error bars represent the standard deviation of calculations of 5 samples. $\mathbf{c}, \mathbf{e}, \mathbf{g}$ Radial distribution function of water molecules around anions sitting at cavity center and window center. $\mathrm{Cl}^{-}$ ions have a weaker second hydration shell compared with $\mathrm{F}^{-}$ions at $0.0457 \mathrm{M}$ when sitting at cavity center (c, e). However, at $3.748 \mathrm{M}, \mathrm{F}^{-}$ions have a relative smaller hydration shell as part of water molecules within second shell were shared with neighbored $\mathrm{F}^{-}$ions $(\mathrm{g})$. $\mathbf{d}, \mathbf{f}, \mathbf{h}$ The simulation cartoon shows the arrangement of water molecules around anions sitting at cavity center (left) and window center (right), corresponding to c, e and g, respectively. Water molecules are red $(\mathrm{O})$ and white $(\mathrm{H})$, and ions $\left(\mathrm{F}^{-}\right.$or $\left.\mathrm{Cl}^{-}\right)$are dark blue. $\mathrm{F}^{-}$ions have two hydration layers at cavity center, and the second hydration shell should peel off at window center at $0.0457 \mathrm{M}(\mathrm{d}) . \mathrm{Cl}^{-}$ions do not have a distinct second hydration shell ( $\mathrm{f}$ ), thus, smaller dehydration energy would be required for transport through windows compared with $\mathrm{F}^{-}$ions at $0.0457 \mathrm{M}$. At $3.748 \mathrm{M}$, water molecules of $\mathrm{F}^{-}$second hydration shell are shared with neighbored $\mathrm{F}^{-}$ions (h)

XPS results suggest that the $\mathrm{F}^{-}$ion has strong interactions with $\mathrm{Zr}$ sites in UiO-66 channels (Supplementary Fig. 6d and Supplementary Tables 3,4), and thus a much higher concentration ( 100 times, Supplementary Table 4$)$ than $\mathrm{Cl}^{-}$. To model the strong $\mathrm{F}-\mathrm{Zr}$ binding, we manually increased the magnitude of parameter epsilon $(\varepsilon)$ in the Lennard-Jones potential that characterizes the van der Waals (vdW) interaction strength between $\mathrm{F}^{-}$and $\mathrm{Zr}$ sites ${ }^{47}$. To estimate the thermodynamic equilibrium $\mathrm{F}^{-}$concentration in $\mathrm{UiO}-66$ channels at the increased $\varepsilon$ values, we adopted a relatively simple MD simulation model (Supplementary Fig. 10). Our model includes a UiO-66 slab (with several half cavities exposed at surfaces) connected to two electrolyte reservoirs having a constant electrolyte ion concentration of $1.0 \mathrm{M}$. After thermodynamic equilibration in MD simulations, the ion/water number ratio in the half cavities was used to estimate the ion concentration in UiO-66. At $15 \varepsilon$, the $\mathrm{F}^{-}$ion concentration is approximately $3.6 \mathrm{M}$. Our MD simulations (details in Methods) show that placing $96 \mathrm{~F}^{-}$ions in the UiO-66 supercells leads to equilibrium concentration of $3.748 \mathrm{M}$ (i.e., $\sim 3.6 \mathrm{M}$ ). This concentration is about 82 times higher than the dilute case $(0.0457 \mathrm{M})$ in our MD simulations, very near the concentration difference measured in experiments (Supplementary Table 4). In these supercells, the $\mathrm{F}^{-}$mobility is calculated as $0.0139 \pm 0.0015$ (unit: $10^{-4} \mathrm{~cm}^{2} \mathrm{~V}^{-1} \cdot \mathrm{s}^{-1}$ ), which is about one quarter of the $\mathrm{Cl}^{-}$ion mobility at $0.0457 \mathrm{M}$. The ion conductivity ratio of $\mathrm{F}^{-} / \mathrm{Cl}^{-}$is thus $\left(3.748 \times 0.0139 \times 10^{-4}\right) /(0.0457 \times 0.058 \times$ $\left.10^{-4}\right)=\sim 20$, which lies in the range (10-50) of experimental observations of PET-UiO-66 channels presented in Fig. 5c. Our experiments and $\mathrm{MD}$ simulations results indicate that the observed high $\mathrm{F}^{-} / \mathrm{Cl}^{-}$selectivity derives from the high $\mathrm{F}^{-}$ concentration in the UiO-66 channels, which, in turn, arises from the strong binding between $\mathrm{F}^{-}$ions and $\mathrm{Zr}$ sites in $\mathrm{UiO}-66$ channels, which is analogous to the natural fluoride ion channels.

Interestingly, our MD simulations show a much higher $(\sim 10$ times) $\mathrm{F}^{-}$ion mobility in the UiO-66 channels at an external electrolyte concentration of $3.748 \mathrm{M}$ relative to that at $0.0457 \mathrm{M}$ (Fig. 4b). This result is opposite to the bulk electrolyte result. Considering that $\mathrm{F}^{-}$ion transport in UiO-66 channels is an activated hopping process between cavities (Fig. 4c, d), the ion concentration (which affects ion hydration in the cavities) and specific ion-channel interactions (mainly through $\mathrm{F}-\mathrm{Zr}$ ) should be the two primary factors influencing ion mobility. To examine their effects, we first reduced the $\mathrm{F}-\mathrm{Zr}$ interaction strength from $15 \varepsilon$ to $1 \varepsilon$, while keeping the $\mathrm{F}^{-}$concentration at $3.748 \mathrm{M}$. The small mobility changes in Fig. $4 \mathrm{~b}$ as a result of this change suggest that the ion concentration plays a dominant role. Analysis of our MD simulations shows that all ions were mobile (Supplementary Fig. 11). Stronger F-Zr interactions do not necessarily lead to immobilization of ions. Next, we reduced the $\mathrm{F}^{-}$concentration to $0.0457 \mathrm{M}$, where $\mathrm{F}^{-}$mobility is always lower, and varied the interaction strength, again resulting in small mobility changes
(Fig. 4b). Our MD results, therefore, indicate that although the strong ion-channel $(\mathrm{F}-\mathrm{Zr})$ binding plays a direct role in ion adsorption concentration (thermodynamics), its direct effect on mobility (kinetics) is minor.

To gain further molecular level insights, the water RDFs surrounding $\mathrm{F}^{-}$ions were calculated at the centers of the nanometer-sized cavities and sub-1-nanometer-sized windows for $\mathrm{F}^{-}$concentration of $3.748 \mathrm{M}$ (Fig. $4 \mathrm{~g}$ ). A comparison with Fig. 4c does not reveal significant differences. But careful inspection of the molecular cartoons in Fig. 4h shows that some water molecules in the second hydration shell are shared with neighboring $\mathrm{F}^{-}$ions. This tendency may also be reflected by the slight increase in the second hydration shell position at high concentration. To illustrate the shared second hydration shell in $g$ $(r)$, we applied a cut-off in Fig. $4 \mathrm{~g}$. The cut-off radius values were selected according to the averaged distances among $\mathrm{F}^{-}$ions, which were determined from the radial distribution function of $\mathrm{F}^{-}$ions around a $\mathrm{F}^{-}$ion fixed in the large cavity center and window center of UiO-66 (Supplementary Fig. 12). For $\mathrm{F}^{-}$ sitting at the window center, there is only a minor change in $g(r)$, and the molecular cartoon also shows the first hydration shell is largely to be intact. Our results suggest that the weaker second hydration shell (or partially dehydrated anion) at high concentration might be the reason for the enhanced mobility.

Ion concentration and $\mathbf{p H}$ effects on $\mathrm{F}^{-} / \mathrm{Cl}^{-}$selectivity. The dependence of ionic conductivity on ion concentrations in the aqueous solutions contiguous to the nanochannels was studied by varying $\mathrm{KF}$ and $\mathrm{KCl}$ concentrations from 0.01 to $1.0 \mathrm{M}$ (see Supplementary Fig. 13 for $I-V$ curves at different external electrolyte solution concentrations). In the pristine PET-nanochannel, the chloride ion conductivity is slightly higher than that of fluoride at the same concentration, consistent with the slightly smaller diameter of hydrated chloride $(6.64 \AA)$ relative to hydrated fluoride (7.04 A) (Supplementary Fig. 14 and Supplementary Table 1). For UiO-66-X filled PET nanochannels, the $\mathrm{F}^{-}$ conductivity is much higher than that of $\mathrm{Cl}^{-}$at the same voltage and concentration. In addition, both $\mathrm{F}^{-}$and $\mathrm{Cl}^{-}$conductivities increase with increasing ion concentration, but $\mathrm{F}^{-}$conductivity rises more dramatically than that of $\mathrm{Cl}^{-}$(Fig. 5a, b). Since PET$\mathrm{UiO}-66-\mathrm{X}$ nanochannels are $\mathrm{F}^{-}$selective, the higher the concentration of $\mathrm{F}^{-}$in the contiguous solutions, the more $\mathrm{F}^{-}$ions can enter the MOF channels, which results in a higher $\mathrm{F}^{-}$concentration, as well as a higher $\mathrm{F}^{-}$mobility in the nanochannels, according to $\mathrm{MD}$ simulations. The $\mathrm{F}^{-} / \mathrm{Cl}^{-}$selectivity of the pristine PET-nanochannel remains quite similar to that of bulk solution and is below 1 (Fig. $5 \mathrm{c}$ ). In marked contrast, the $\mathrm{F}^{-} / \mathrm{Cl}^{-}$ selectivities for $\mathrm{UiO}-66$, $\mathrm{UiO}-66-\mathrm{NH}_{2}$ and $\mathrm{UiO}-66-\mathrm{N}^{+}\left(\mathrm{CH}_{3}\right)_{3}$ filled PET nanochannels increase with the decreasing of MOF pore sizes, and the $\mathrm{F}^{-} / \mathrm{Cl}^{-}$selectivity of the PET-UiO-66-N $\mathrm{N}^{+}\left(\mathrm{CH}_{3}\right)_{3}$ 

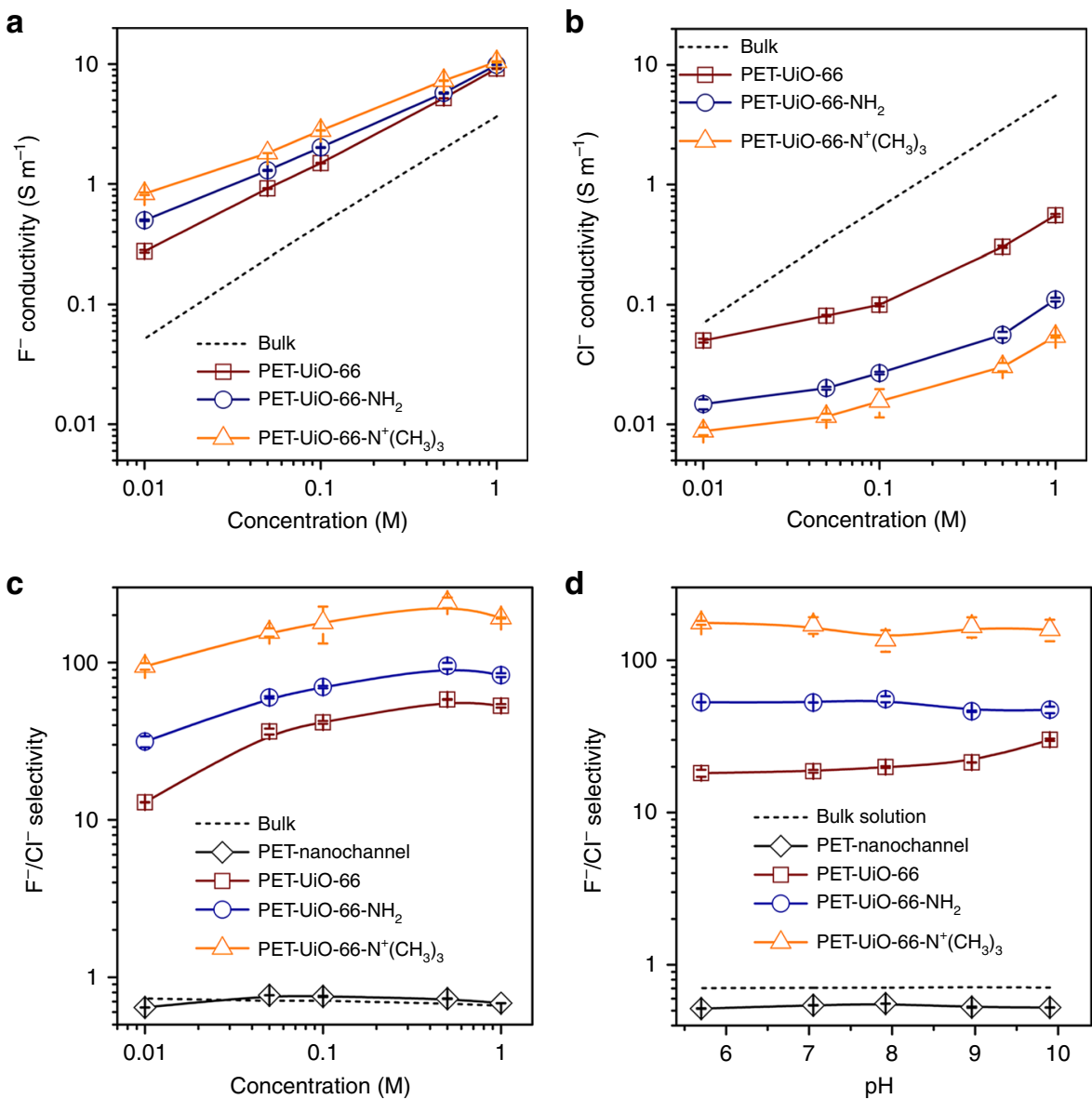

Fig. 5 Influence of concentration and $\mathrm{pH}$ on $\mathrm{F}^{-}, \mathrm{Cl}^{-}$conductivity and $\mathrm{F}^{-} / \mathrm{Cl}^{-}$selectivity. $\mathbf{a}, \mathbf{b} \mathrm{F}^{-}$and $\mathrm{Cl}^{-}$conductivities in $\mathrm{PET}-\mathrm{UiO}-66-\mathrm{X}$ nanochannels as a function of ion concentration. $\mathrm{F}^{-}$conductivities in UiO-66-X nanochannels are much higher than those in bulk solution, while $\mathrm{Cl}^{-}$conductivities in UiO-66$\mathrm{X}$ nanochannels are much lower than those in bulk solution. $\mathbf{c ~} \mathrm{F}^{-} / \mathrm{Cl}^{-}$selectivity of PET-UiO-66-X nanochannels as a function of ion concentration. Among the MOFs considered, the UiO-66- $\mathrm{N}^{+}\left(\mathrm{CH}_{3}\right)_{3}$ nanochannel exhibits the highest $\mathrm{F}^{-} / \mathrm{Cl}^{-}$selectivity $(\sim 240)$. d $\mathrm{F}^{-} / \mathrm{Cl}^{-}$selectivity of PET-UiO-66-X nanochannels measured in $0.1 \mathrm{M} \mathrm{KF}$ and $\mathrm{KCl}$ solutions at different $\mathrm{pH}$ values. Error bars represent the standard deviation of three measurements of a sample

nanochannel increased from $\sim 95$ to $\sim 240$ as external salt concentration rose from 0.01 to $0.5 \mathrm{M}$ (Fig. $5 \mathrm{c}$ ).

Since the $\mathrm{Zr}$-nodes and amino groups on these MOFs are sensitive to $\mathrm{pH}$, we measured conductivities of PET-UiO-66-X nanochannels in $0.1 \mathrm{M}$ electrolyte solutions while varying $\mathrm{pH}$ from 5.7 to 10 . Relative to the nearly constant conductivities of bulk electrolyte solutions at different $\mathrm{pH}$ values (Supplementary Fig. 15a), ionic conductivities of the pristine PET-nanochannel increase with the increasing electrolyte solution $\mathrm{pH}$ (Supplementary Fig. 15b). The $\mathrm{p} K_{\mathrm{a}}$ of the COOH group of PET is $\sim 3.8$; as $\mathrm{pH}$ increases from 5.7 to 10 , the PET-nanochannel becomes more negatively charged, since more $\mathrm{COOH}$ groups are deprotonated, thus attracting more cations to transport through the channel. However, as for UiO-66, the $\mathrm{p} K_{\mathrm{a}}$ values of the $\mu_{3}-\mathrm{OH}, \mathrm{Zr}-\mathrm{OH}_{2}$, and $\mathrm{Zr}-\mathrm{OH}$ groups on the $\mathrm{Zr}$-nodes are about 3.52, 6.79, and 8.30, respectively; for $\mathrm{UiO}-66-\mathrm{NH}_{2}$, the $\mathrm{p} K_{\mathrm{a}}$ of the $\mathrm{NH}_{2}$ group on the ligand is about $58-50$; for $\mathrm{UiO}-66-\mathrm{N}^{+}\left(\mathrm{CH}_{3}\right)_{3}$, the framework is positively charged due to the quaternary ammonium groups (Supplementary Fig. 5). As $\mathrm{pH}$ in $\mathrm{KF}$ or $\mathrm{KCl}$ solution increases from 5.7 to 10 , the degree of protonation degrees of the three MOFs vary insignificantly, as indicated by the zeta potential values shown in Supplementary Table 9. Consequently, $\mathrm{F}^{-}$and $\mathrm{Cl}^{-}$conductivities of the PET-UiO-66-X nanochannels are independent of $\mathrm{pH}$ over the range from 5.7 to 10 (Supplementary Fig. $15 \mathrm{c}-\mathrm{e}$ ). The $\mathrm{F}^{-} / \mathrm{Cl}^{-}$selectivity of
PET-UiO-66-X nanochannels varies slightly as $\mathrm{pH}$ increases from 5.7 to 10 , and the selectivity values are extraordinarily higher than those of the pristine PET-nanochannel or bulk solution, which have a selectivity of less than 1 . (Fig. $5 \mathrm{~d}$ ).

Fluoride ion selectivity over other anions in MOF channels. The selectivity of $\mathrm{F}^{-}$over other anions in the PET-UiO-66- $\mathrm{NH}_{2}$ nanochannel was investigated by measuring the ionic currents with various electrolyte solutions including $\mathrm{KCl}, \mathrm{KBr}, \mathrm{KI}, \mathrm{KNO}_{3}$, $\mathrm{K}_{2} \mathrm{SO}_{4}$, and $\mathrm{KF}(0.1 \mathrm{M}, \mathrm{pH}$ 5.7). As discussed earlier, the UiO-66$\mathrm{NH}_{2}$ framework is positively charged in solution due to the $\mathrm{Zr}$-sites present on the framework. Consequently, smaller anions can conduct faster through UiO-66- $\mathrm{NH}_{2}$ channels, while cations (i.e., $\mathrm{K}^{+}$) are blocked. From the $I-V$ curves of a PET-UiO$66-\mathrm{NH}_{2}$ nanochannel, the absolute ionic current of $\mathrm{F}^{-}$at any voltage is much higher than that of other anions under the same conditions (Supplementary Fig. 16a, b), and their ionic current values decrease as dehydrated ionic diameter increases (Supplementary Table 1). In bulk solution and a pristine PET-nanochannel, conductivities of the hydrated monovalent anions decrease with increasing hydrated anionic diameters (Supplementary Table 1), while the divalent anion $\mathrm{SO}_{4}{ }^{2-}$ (hydrated ionic diameter of $7.58 \AA$ ) exhibits a higher conductivity than other hydrated monovalent anions (Supplementary Fig. 16c, d and 

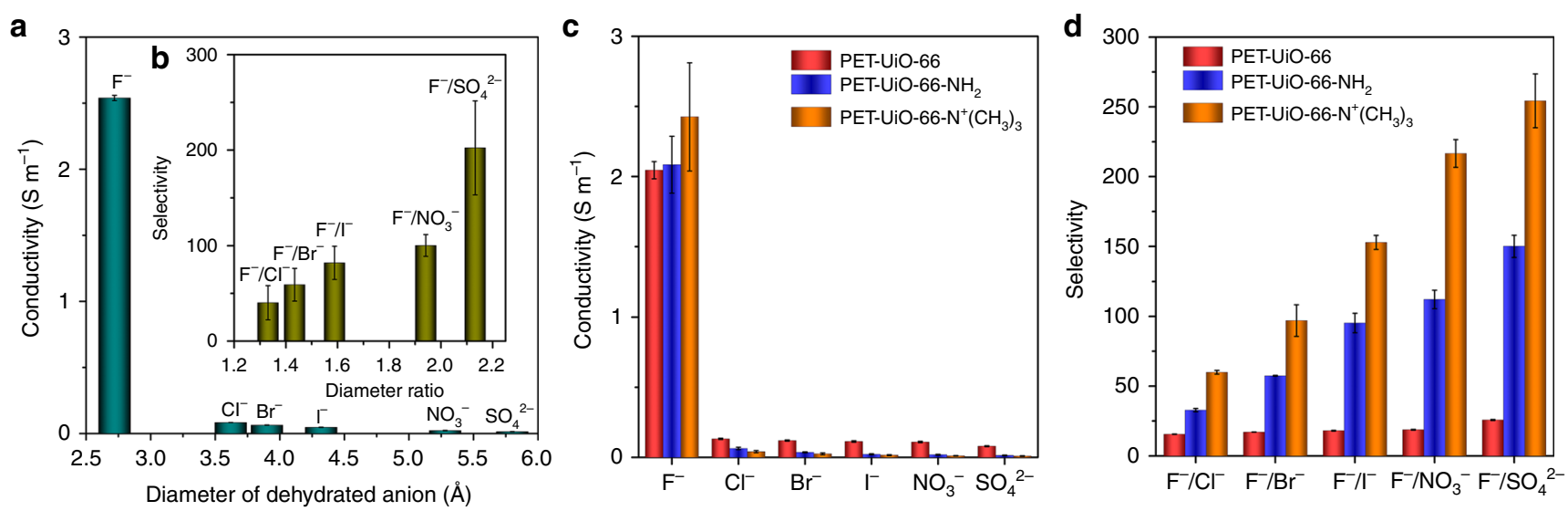

Fig. $6 \mathrm{~F}^{-}$selective properties of PET-UiO-66-X nanochannels. a lonic conductivities of a PET-UiO-66-NH $\mathrm{N}_{2}$ nanochannel decrease as dehydrated anion diameters increase. $\mathbf{b}$ Average ion selectivity as a function of dehydrated anion diameter ratio (Selectivity $=k_{\mathrm{F}^{-}} / k_{\text {Anion, }}$, diameter ratio $=d_{\text {Anion }} / d_{\mathrm{F}^{-}}$). Error bars represent the standard deviation of independent measurement of three samples. $\mathbf{c}$, $\mathbf{d}$ Systematic comparison of ionic conductivities and selectivities of PET-UiO-66, PET-UiO-66- $\mathrm{NH}_{2}$, and PET-UiO-66- $\mathrm{N}^{+}\left(\mathrm{CH}_{3}\right)_{3}$ nanochannels. The PET-UiO-66- $\mathrm{N}^{+}\left(\mathrm{CH}_{3}\right)_{3}$ nanochannel exhibits the highest $\mathrm{F}^{-}$conductivity and selectivity. All data were obtained using $0.1 \mathrm{M}$ electrolyte solutions at a $\mathrm{pH}$ value of 5.7. Error bars represent the standard deviation of three measurements of a sample

Supplementary Table 1). In PET-UiO-66- $\mathrm{NH}_{2}$ nanochannels, however, anions conductivities decrease as dehydrated ion diameters increase, and $\mathrm{F}^{-}$ions conduct much faster than other anions, owning to the specific binding effect discussed earlier (Fig. 6a). The average anion selectivity increased from a $\mathrm{F}^{-} / \mathrm{Cl}^{-}$ selectivity of $40.2 \pm 17.9$ to a $\mathrm{F}^{-} / \mathrm{SO}_{4}{ }^{2-}$ of $202.4 \pm 49.2$ as dehydrated ionic diameters increase (Fig. 6b; see Supplementary Table 10 for individual test results), which is much higher than that measured in a pristine PET-nanochannel or bulk solution (Supplementary Fig. 16e). The UiO-66 and UiO-66- $\mathrm{N}^{+}\left(\mathrm{CH}_{3}\right)_{3}$ nanochannels display conductivity and selectivity similar to those of the UiO-66- $\mathrm{NH}_{2}$ nanochannel (Fig. $6 c$, d).

Cycle performance and stability of MOF channels. To confirm the cyclability of PET-UiO-66-X nanochannels, ion current values of $\mathrm{KF}, \mathrm{KCl}, \mathrm{KBr}$, and $\mathrm{KI}$ solutions $(0.1 \mathrm{M}, \mathrm{pH} 5.7)$ were cyclically tested. After testing for at least three cycles, no obvious attenuation in current was observed in PET-UiO-66- $\mathrm{NH}_{2}$ nanochannels (Supplementary Fig. 17). XRD patterns of UiO-66-X crystals before and after treatment in $\mathrm{KF}, \mathrm{KCl}, \mathrm{KBr}$, and $\mathrm{KI}$ solutions for 3 days demonstrated the stability of UiO-66-X MOFs (Supplementary Fig. 18). Furthermore, the BET surface areas and pore size distributions of $\mathrm{UiO}-66-\mathrm{NH}_{2}$ crystals show only minor changes before and after treatment in $\mathrm{KF}, \mathrm{KCl}, \mathrm{KBr}$, and KI solutions for 3 days (Supplementary Fig. 19).

\section{Discussion}

In summary, highly conductive and selective fluoride ion channels have been constructed by in-situ growth of $\mathrm{Zr}$-based UiO-66 derivative MOFs into asymmetric single-nanochannel PET membranes. The PET-UiO-66-X nanochannels exhibit remarkably high selectivity for $\mathrm{F}^{-}$over $\mathrm{Cl}^{-}, \mathrm{Br}^{-}, \mathrm{I}^{-}, \mathrm{NO}_{3}{ }^{-}$, and $\mathrm{SO}_{4}{ }^{2-}$. Our experiments and $\mathrm{MD}$ simulations indicate that the high $\mathrm{F}^{-}$ concentration, arising from the strong interaction between $\mathrm{F}^{-}$ ions and binding sites in UiO-66 channels, is the primary reason for the observed high $\mathrm{F}^{-} / \mathrm{Cl}^{-}$selectivity. Note that the enhanced $\mathrm{F}^{-}$ion mobility at a high concentration (compared with a low concentration) in UiO-66 channels also contributes to the high selectivity. The high-performance synthetic $\mathrm{F}^{-}$ion channels demonstrated here provide an attractive strategy for developing artificial fluoride ion channel membranes for applications such as efficient removal of toxic fluoride ions from water. Furthermore,
MOFs with tailorable angstrom-sized pores have great potential as platforms for constructing other ion channels and separation membranes.

\section{Methods}

Materials. Zirconium (IV) chloride $\left(\mathrm{ZrCl}_{4}\right)$, benzene-1,4-dicarboxylic acid or terephthalic acid (BDC), 2-aminoterephthalic acid $\left(\mathrm{BDC}-\mathrm{NH}_{2}\right)$, dimethylformamide $(\mathrm{DMF})$, iodomethane $\left(\mathrm{CH}_{3} \mathrm{I}\right)$, potassium fluoride $(\mathrm{KF})$, potassium chloride $(\mathrm{KCl})$, potassium bromide $(\mathrm{KBr})$, potassium iodide $(\mathrm{KI})$, potassium nitrate $\left(\mathrm{KNO}_{3}\right)$, potassium sulfate $\left(\mathrm{K}_{2} \mathrm{SO}_{4}\right)$, sodium dodecyl diphenyloxide disulfonate, formic acid $(\mathrm{HCOOH})$ and hydrochloric acid $(\mathrm{HCl})$ were purchased from Sigma-Aldrich, Australia. Methanol, ethanol, potassium hydroxide $(\mathrm{KOH})$ and sodium hydroxide $(\mathrm{NaOH})$ were purchased from Merck, Australia. PET membranes were obtained from Hostaphan RN12 Hoechst, Germany.

Nanochannels preparation. PET membranes $(12 \mu \mathrm{m}$ thick, with single or multiple ion tracks in the center) were simultaneously etched from one side with $6 \mathrm{M}$ $\mathrm{NaOH}+0.025 \%$ sodium dodecyl diphenyloxide disulfonate and the other side with $6 \mathrm{M} \mathrm{NaOH}$ etching solution at $60^{\circ} \mathrm{C}$ to produce single or multiple bullet-shaped nanochannels. A Keithley 6487 picoammeter (Keithley Instruments, Cleveland) was employed to observe the changing current of the single-nanochannel membrane during etching. The etching process was terminated by adding a mixture of $1.0 \mathrm{M} \mathrm{KCl}$ and $1.0 \mathrm{M} \mathrm{HCOOH}$ aqueous solution, which neutralized the alkaline etching solution. The morphologies and diameters of the nanochannels were observed by SEM using multichannel membranes prepared under the same etching conditions as single channel membranes.

Modification of single nanochannels with UiO-66-X MOFs. $\mathrm{ZrCl}_{4}(150 \mathrm{mg})$ and BDC $(106 \mathrm{mg})$ or BDC- $\mathrm{NH}_{2}(120 \mathrm{mg})$ in DMF $(25 \mathrm{~mL})$ were ultrasonically dissolved in a glass bottle. The resulting clear solution was transferred into a Teflon-lined stainless-steel autoclave, in which the PET membrane with a singlenanochannel was secured vertically with a holder. Subsequently, the autoclave was placed in an oven and heated at $100^{\circ} \mathrm{C}$ for $24 \mathrm{~h}$. After cooling to room temperature, the as-prepared nanochannel membrane was washed with ethanol three times, followed by drying at room temperature overnight. Finally, the resulting singlechannel membrane was immersed into $\mathrm{CH}_{3} \mathrm{I}$ methanol solution for $72 \mathrm{~h}$ for the quaternization process, followed by washing with methanol three times and drying at room temperature overnight.

\section{Current measurement. The current measurements were carried out with a} Keithley 6487 picoammeter (Keithley Instruments, Cleveland), and a PET membrane with a single-channel was placed between two cells (Supplementary Fig. 4a, b). One platinum (Pt) electrode was placed in each cell and employed to apply a voltage across the nanochannel. The tip side of the nanochannel faced the anode, and the base side faced the cathode. A scanning voltage from $-2 \mathrm{~V}$ to $+2 \mathrm{~V}$ with a period of $20 \mathrm{~s}$ was applied three times. For measurements of the anion selective transport properties of the nanochannel, different solutions including $\mathrm{KF}, \mathrm{KCl}$, $\mathrm{KBr}, \mathrm{KI}, \mathrm{KNO}_{3}$, and $\mathrm{K}_{2} \mathrm{SO}_{4}$ were added to both cells, respectively. The selectivity of $\mathrm{F}^{-}$over $\mathrm{Cl}^{-}, \mathrm{Br}^{-}, \mathrm{I}^{-}, \mathrm{NO}_{3}{ }^{-}$, and $\mathrm{SO}_{4}{ }^{2-}$ was studied by recording the ionic current during the potential scan resulting from anions transport through the nanochanne. 
Molecular dynamics (MD) simulations. The simulation system is a supercell composed of $2 \times 2 \times 2$-unit cells of UiO- 66 . We adopted the force field parameters from reference $\mathrm{S}^{51}$ for UiO-66. The original TIP/3 P model was adopted for water, and the SHAKE algorithm was employed to permit a longer simulation and partially reduce the statistical error. The LJ parameters potentials of ions were taken from the DANG force field ${ }^{52}$. The Lorentz-Berthelot mixing rule was used to determine LJ potential parameters between different types of ions, water molecules and atoms of UiO-66. The detailed LJ potential parameters and partial charges are summarized in Supplementary Table 11. All simulations employed a $10 \AA$ cut-off for van der Waals (vdW) interactions using modified LJ potential, short-range electrostatic forces, and long-range electrostatics that employed the particle-particle particle-mesh (PPPM) algorithm. All simulations were performed using the LAMMPS code.

A slab model to estimate equilibrium $\mathbf{F}^{-}$concentration. The concentration effect arising from the strong $\mathrm{F}-\mathrm{Zr}$ interaction was examined via simulating the ion absorption at UiO-66 surface. A UiO-66 slab whose surfaces had several exposed half cavities was created (Supplementary Fig. 20a). This slab was connected to two reservoirs with electrolyte at a $\mathrm{F}^{-}$concentration of $1.0 \mathrm{M}$. MD simulations were run under NVT ensemble conditions at $300 \mathrm{~K}$. We checked the ion concentration in the reservoir during the MD simulations and gradually inserted more ions to maintain its concentration at $1.0 \mathrm{M}$. After thermal equilibrium for $15 \mathrm{~ns}$, we calculated the average ion concentration distribution along the direction perpendicular to the slab surface. Supplementary Fig. 20b summarizes the $\mathrm{F}^{-}$concentration inside the half-exposed cavities at the slab surface. The ion concentration in the cavities was then estimated as the number ratio of ions over water.

Determination of water molecule number density within Ui0-66 supercells. To determine the number of water molecules within UiO-66 supercells at thermoequilibrium, we performed MD simulations on a UiO-66 slab connected with two reservoirs (or gaps) filled with water (Supplementary Fig. 10). Initially, the MOF supercells were filled with a prescribed number of ions (e.g., 1 ion in a $2 \times 2 \times 2$ UiO-66 supercell or 96 ions in a $2 \times 2 \times 2$ UiO-66 supercell) but no water molecules. We then ran MD simulations under an NVT ensemble to allow diffusion of water molecules diffused into the UiO-66 frameworks. Meanwhile, we gradually inserted more water molecules in the reservoirs to make the number density close to the value at ambient conditions. When the water number density in the reservoirs showed no changes for $\sim 10 \mathrm{~ns}$, we considered the systems to have reached the equilibrium conditions. Using the ratio of the number of ions to the number of water molecule number in the UiO-66 supercells, we were able to determine the ion concentration, i.e., 1 ion in the $2 \times 2 \times 2$ supercell corresponding to $0.0457 \mathrm{M}$, and the 96 ions in the $2 \times 2 \times 2$ supercell corresponding to $3.748 \mathrm{M}$.

\section{Applying external electric fields to determine ion mobility. NVT ensemble} simulations were performed at $298 \mathrm{~K}$. The time step was $1 \mathrm{fs}$, and an external electric field of $0.1 \mathrm{~V}^{-1}$ was applied. Using external electric fields to calculate ion mobility is a widely accepted practice in previous studies, including ion transport in bulk aqueous solutions $\mathrm{s}^{52,53}$ and ion transport in nano-channels ${ }^{54-59}$. The electric field strength chosen in this study, i.e., $0.1 \mathrm{~V} \AA^{-1}$, has been frequently used ${ }^{57,59}$ and is far below $1 \mathrm{~V} \AA^{-1}$ (the upper bound of eletric field strength, beyond which the polarization of water molecules is notable $)^{60,61}$. Results generated during the last 35 ns were used to calculate the ion flow velocity and radial distribution function. The mobility values $(\mu)$ were calculated via:

$$
\langle\mu(t)\rangle=\langle V\rangle / E
$$

where $E$ is the electric field strength $\left(0.1 \mathrm{~V} \AA^{-1}\right)$, and $V$ is the drift velocity. $V$ is collected from the displacement of the ions in the presence of electric field. The ion displacement profiles (Supplementary Fig. 21) show that $\mathrm{Cl}^{-}$ions (at $0.0457 \mathrm{M}$ ) and $\mathrm{F}^{-}$ions (at $0.0457 \mathrm{M}$, or at concentration $3.748 \mathrm{M}$ ) are crossing pore windows repeatedly during mobility calculations. However, $\mathrm{F}^{-}$ions (at $0.0457 \mathrm{M}$ and using standard F-Zr LJ interaction strengths) crossed the pore window once during that $\sim 35 \mathrm{~ns}$. Thus, we performed an additional $4 \mathrm{MD}$ simulations (for around $250 \mathrm{~ns}$, collecting displacement values for $224 \mathrm{~ns}$ ) for $\mathrm{F}^{-}$ions at low concentration with the standard F-Zr LJ strength in order to obtained more accurate mobility results.

Potential of mean force calculations. Using the collective variables (colvars) package developed by Fiorin and co-workers ${ }^{62}$, umbrella sampling calculations were performed within LAMMPS. The target ion was confined by a $40 \mathrm{kcal} \mathrm{mol}^{-1}$ $\AA^{-2}$ harmonic restraint acting along the reaction coordinate, with 30 umbrellas each having an approximate spacing of $0.3 \AA$. In each umbrella, the target ion was placed at the harmonic center. After $2 \mathrm{~ns}$ of NVT equilibrium at $300 \mathrm{~K}$ was run, we recorded the positions of the target ion along the reaction coordinate direction within each umbrella was recorded at $1000 \mathrm{fs}$ intervals over a $4 \mathrm{~ns}$ NVT production period. The weighted histogram analysis method (WHAM) was utilized to combine the different umbrella simulations into a free energy curve ${ }^{63}$. Supplementary Fig. 8 depicts the 30 histograms of $\mathrm{F}^{-}$and $\mathrm{Cl}^{-}$ions at different positions along the straight line that connects the large cavity center to the small cavity center. Supplementary Fig. 9 shows the PMF results.
Diffusion coefficients calculations. The self-diffusion coefficient of ions in UiO66 channels is calculated by weighting the hopping rates out of the 8-coordinated cavity sites $\left(k_{A \rightarrow B}\right)$ and 4-coordinated cavity sites $\left(k_{B \rightarrow A}\right)$ by including the following weighting factors in the equation to modify the equilibrium probability of occupying cavity $\mathrm{A}\left(P_{A}\right)$ and $\mathrm{B}\left(P_{B}\right): 45$

$$
D_{S}=\frac{1}{6} \lambda^{2}\left(8 k_{A \rightarrow B} P_{A}+4 k_{B \rightarrow A} P_{B}\right)
$$

where $\lambda(8.98 \AA)$ is the hopping distance between adjacent cavities. Since the likelihood of occupying a site is directly proportional to the residence time in each site (the inverse of the hopping rate), the occupancy probabilities can be eliminated, yielding

$$
D_{S}=\frac{1}{6} \lambda^{2}\left(8 k_{A \rightarrow B}\left(\frac{k_{B \rightarrow A}}{2 k_{A \rightarrow B}+k_{B \rightarrow A}}\right)+4 k_{B \rightarrow A}\left(\frac{2 k_{A \rightarrow B}}{2 k_{A \rightarrow B}+k_{B \rightarrow A}}\right)\right)
$$

The hopping rates $k_{A \rightarrow B}$ and $k_{B \rightarrow A}$ were calculated by applying 1-dimentional transition state theory (TST)

$$
k_{A \rightarrow B}=k \sqrt{\frac{k_{B} T}{2 \pi m}} \frac{e^{-\beta F(q *)}}{\int_{\text {Cage }} e^{-\beta F(q)} d q}
$$

where $m$ is the mass of the adsorbate molecule and $k$ is the Bennett-Chandler dynamic correction factor, which was assumed to be 1 in this work ${ }^{64} . F\left(q^{*}\right)$ is the free energy at the transition states. The denominator of equation (4) was evaluated by integrating over the points on the reaction coordinate associated with the respective cavity microstates. We estimated the self-diffusion coefficient to be $7.60 \times$ $10^{-10} \mathrm{~cm}^{2} \mathrm{~s}^{-1}$ (which converts to a mobility value of $2.96 \times 10^{-8} \mathrm{~cm}^{2} \mathrm{~V}^{-1} \cdot \mathrm{s}^{-1}$ using Einstein relation) and $9.40 \times 10^{-8} \mathrm{~cm}^{2} \mathrm{~s}^{-1}$ (which converts to a mobility value of $3.66 \times 10^{-6} \mathrm{~cm}^{2} \mathrm{~V}^{-1} \cdot \mathrm{s}^{-1}$ ) for $\mathrm{F}^{-}$and $\mathrm{Cl}^{-}$ions, respectively. These values agree reasonably well with our mobility data $1.5 \times 10^{-7} \mathrm{~cm}^{2} \mathrm{~V}^{-1} \cdot \mathrm{s}^{-1}$ for $\mathrm{F}^{-}$ions and $6 \times 10^{-6} \mathrm{~cm}^{2} \mathrm{~V}^{-1} \cdot \mathrm{s}^{-1}$ for $\mathrm{Cl}^{-}$ions, calculated in MD simulations using the external electric field methods. This further confirms the reliability of the electric field method.

Powder X-ray diffraction (PXRD). XRD patterns were recorded in the $2 \theta$ range of $2-50^{\circ}$ at room temperature using a Miniflex 600 diffractometer (Rigaku, Japan) in transmission geometry, using $\mathrm{Cu} \mathrm{Ka}$ radiation $(15 \mathrm{~mA}$ and $40 \mathrm{kV})$ at a scan rate of $2^{\circ} \mathrm{min}^{-1}$ and a step size of $0.02^{\circ}$.

Scanning electron microscopy (SEM). SEM images were taken with a fieldemission scanning electron microscope (FEI Magellan 400 FEG SEM) operating at $5 \mathrm{kV}, 13 \mathrm{pA}$.

X-ray photoelectron spectroscopy (XPS). XPS spectra were recorded using a Kratos Axis UltraDLD instrument (KratosLtd., Telford, UK) that is equipped with a monochromated Alka $(1486 \mathrm{eV})$ source operating at $150 \mathrm{~W}(15 \mathrm{kV}$ and $10 \mathrm{~mA})$. The photoelectron take-off angle with respect to the normal surface in all measurements was $0^{\circ}$.

Zeta potential. Zeta potentials of UiO-66-X crystals were measured and analyzed using a Zeta Sizer (Nano Series).

Gas adsorption and desorption measurement. For gas adsorption/desorption isotherms, high-purity grade (99.999\%) nitrogen was used throughout the experiments. Prior to gas adsorption/desorption measurement, UiO-66-X powders were activated at $140{ }^{\circ} \mathrm{C}$ for $24 \mathrm{~h}$. Low pressure volumetric nitrogen adsorption/ desorption isotherms up to 1 bar were measured by a Micromeritics 3 Flex gas sorption analyzer. BET surface areas and pore sizes were determined by measuring $\mathrm{N}_{2}$ adsorption/desorption isotherms at $77 \mathrm{~K}$ in a liquid nitrogen bath and calculated using the Micromeritics software. The DFT model was selected for characterizing of the pore size distribution.

Ion conductivity. The ionic conductivity $(\kappa)$ of a nanochannel can be defined as:

$$
\kappa=G \cdot \frac{L}{S}
$$

where $G$ is the conductance of a nanochannel, $S$ is its cross-sectional area, and $L$ is its length. For MOF-filled nanochannels, $S$ is the effective cross-sectional areas of MOF pores, which can be calculated from the pore volume of MOF crystals (see Supplementary Table 12 for further information).

For a bullet-shaped nanochannel, the radius profile $r(x)$ can be described as:

$$
r(x)=\frac{r_{b}-r_{t} \exp \left(-\frac{L}{h}\right)-\left(r_{b}-r_{t}\right) \exp \left(-\frac{x}{h}\right)}{1-\exp \left(-\frac{L}{h}\right)}
$$

where $r_{b}$ is the base radius, $r_{t}$ is the tip radius, $L$ is the length of a nanochannel, and $h$ is a geometrical parameter characterizing the curvature of a nanochannel profile, designated as the curvature radius, which was observed by fitting the obtained experimental tip profiles ${ }^{65,66}$. 
$L / S$ of a bullet-shaped nanochannel is theoretically described as:

$$
\frac{L}{S}=\int_{0}^{L} \frac{1}{\pi \mathrm{r}^{2}(x)} d x=\int_{0}^{L} \frac{1}{\pi\left[\frac{r_{b}-r_{t} \exp \left(-\frac{L}{h}\right)-\left(r_{b}-r_{t}\right) \exp \left(-\frac{x}{h}\right)}{1-\exp \left(-\frac{L}{h}\right)}\right]^{2}} d x
$$

At high electrolyte concentration (i.e., $1.0 \mathrm{M}$ ) and a $\mathrm{pH}$ value close to the isoelectric point of the surface (3.8), at which the electrical double layer can be neglected and the specific ion conductivity in a nanochannel is equal to that in bulk solution, the $(L / S)_{\mathrm{NC}}$ of a nanochannel can be calculated by:

$$
\left(\frac{L}{S}\right)_{\mathrm{NC}}=\kappa \cdot \frac{U}{I}
$$

where $k$ is the ion conductivity of $1.0 \mathrm{M}$ electrolyte in bulk solution, and $I$ is the ion current measured at the applied voltage $U$. For MOF-filled nanochannels, $(L / S)_{\text {MOF }}$ is calculated by:

$$
\left(\frac{L}{S}\right)_{\mathrm{MOF}}=\left(\frac{L}{S}\right)_{\mathrm{NC}} \cdot \frac{1}{v_{\mathrm{MOF}} d_{\mathrm{calc}}}
$$

where $v$ is the pore volume of MOF crystals and $d_{\text {calc }}$ is the calculated crystal density (see Supplementary Table 12 for further information).

\section{Data availability}

The data that support the findings of this study are available from the corresponding author upon reasonable request.

Received: 6 September 2018 Accepted: 9 May 2019

Published online: 11 June 2019

\section{References}

1. Stockbridge, R. B., Robertson, J. L., Kolmakova-Partensky, L. \& Miller, C. A family of fluoride-specific ion channels with dual-topology architecture. Elife 2, e01084 (2013).

2. Ozsvath, D. L. Fluoride and environmental health: a review. Rev. Environ. Sci. Biotechnol. 8, 59-79 (2008)

3. Kaminsky, L. S., Mahoney, M. C., Leach, J., Melius, J. \& Miller, M. J. Fluoride: benefits and risks of exposure. Crit. Rev. Oral. Biol. Med. 1, 261-281 (1990).

4. Baker, J. L. et al. Widespread genetic switches and toxicity resistance proteins for fluoride. Science 335, 233-235 (2012).

5. Ji, C., Stockbridge, R. B. \& Miller, C. Bacterial fluoride resistance, Fluc channels, and the weak acid accumulation effect. J. Gen. Physiol. 144, 257-261 (2014).

6. Duran, C., Thompson, C. H., Xiao, Q. \& Hartzell, H. C. Chloride channels: often enigmatic, rarely predictable. Annu. Rev. Physiol. 72, 95-121 (2010).

7. Stockbridge, R. B. et al. Crystal structures of a double-barrelled fluoride ion channel. Nature 525, 548-551 (2015)

8. Stockbridge, R. B. et al. Fluoride resistance and transport by riboswitchcontrolled CLC antiporters. Proc. Natl Acad. Sci. USA 109, 15289-15294 (2012).

9. Brammer, A. E., Stockbridge, R. B. \& Miller, C. $\mathrm{F}^{-} / \mathrm{Cl}^{-}$selectivity in $\mathrm{CLC}^{\mathrm{F}}$ type $\mathrm{F}^{-} / \mathrm{H}^{+}$antiporters. J. Gen. Physiol. 144, 129-136 (2014).

10. Stockbridge, R. B., Koide, A., Miller, C. \& Koide, S. Proof of dual-topology architecture of Fluc $\mathrm{F}^{-}$channels with monobody blockers. Nat. Commun. 5 , 5120 (2014).

11. Clarke, H. J. et al. Transmembrane fluoride transport: direct measurement and selectivity studies. J. Am. Chem. Soc. 138, 16515-16522 (2016).

12. Hong, S. U., Malaisamy, R. \& Bruening, M. L. Separation of fluoride from other monovalent anions using multilayer polyelectrolyte nanofiltration membranes. Langmuir 23, 1716-1722 (2007).

13. Vaselbehagh, M., Karkhanechi, H., Takagi, R. \& Matsuyama, H. Surface modification of an anion exchange membrane to improve the selectivity for monovalent anions in electrodialysis-experimental verification of theoretical predictions. J. Membr. Sci. 490, 301-310 (2015).

14. Park, H. B., Kamcev, J., Robeson, L. M., Elimelech, M. \& Freeman, B. D. Maximizing the right stuff: the trade-off between membrane permeability and selectivity. Science 356, eaab0530 (2017).

15. Cui, Y. et al. Metal-organic frameworks as platforms for functional materials. Acc. Chem. Res. 49, 483-493 (2016).

16. Islamoglu, T. et al. Postsynthetic tuning of metal-organic frameworks for targeted applications. Acc. Chem. Res. 50, 805-813 (2017).

17. Seoane, B. et al. Metal-organic framework based mixed matrix membranes: a solution for highly efficient $\mathrm{CO}_{2}$ capture? Chem. Soc. Rev. 44, 2421-2454 (2015).

18. Barea, E., Montoro, C. \& Navarro, J. A. Toxic gas removal-metal-organic frameworks for the capture and degradation of toxic gases and vapours. Chem. Soc. Rev. 43, 5419-5430 (2014).
19. Howarth, A. J. et al. Chemical, thermal and mechanical stabilities of metal-organic frameworks. Nat. Rev. Mater. 1, 15018 (2016).

20. Rubio-Martinez, M. et al. New synthetic routes towards MOF production at scale. Chem. Soc. Rev. 46, 3453-3480 (2017).

21. Denny, M. S. Jr, Moreton, J. C., Benz, L. \& Cohen, S. M. Metal-organic frameworks for membrane-based separations. Nat. Rev. Mater. 1, 16078 (2016).

22. Hu, T. L. et al. Microporous metal-organic framework with dual functionalities for highly efficient removal of acetylene from ethylene/ acetylene mixtures. Nat. Commun. 6, 7328 (2015)

23. Wang, H. et al. Topologically guided tuning of Zr-MOF pore structures for highly selective separation of C6 alkane isomers. Nat. Commun. 9, 1745 (2018).

24. Wang, C., Liu, X., Keser Demir, N., Chen, J. P. \& Li, K. Applications of water stable metal-organic frameworks. Chem. Soc. Rev. 45, 5107-5134 (2016).

25. Hu, Z., Chen, Y. \& Jiang, J. Zeolitic imidazolate framework-8 as a reverse osmosis membrane for water desalination: Insight from molecular simulation. J. Chem. Phys. 134, 134705 (2011).

26. Zhu, Y. et al. Synthesis and seawater desalination of molecular sieving zeolitic imidazolate framework membranes. Desalination 385, 75-82 (2016).

27. Cavka, J. H. et al. A new zirconium inorganic building brick forming metal organic frameworks with exceptional stability. J. Am. Chem. Soc. 130, 13850-13851 (2008).

28. Furukawa, H. et al. Water adsorption in porous metal-organic frameworks and related materials. J. Am. Chem. Soc. 136, 4369-4381 (2014).

29. Liu, X., Demir, N. K., Wu, Z. \& Li, K. Highly water-stable zirconium metalorganic framework UiO-66 membranes supported on alumina hollow fibers for desalination. J. Am. Chem. Soc. 137, 6999-7002 (2015).

30. Zhang, Y. et al. Preparation of nanofibrous metal-organic framework filters for efficient air pollution control. J. Am. Chem. Soc. 138, 5785-5788 (2016)

31. Wang, C., Liu, X., Chen, J. P. \& Li, K. Superior removal of arsenic from water with zirconium metal-organic framework UiO-66. Sci. Rep. 5, 16613 (2015).

32. Plonka, A. M. et al. In situ probes of capture and decomposition of chemical warfare agent simulants by Zr-based metal organic frameworks. J. Am. Chem. Soc. 139, 599-602 (2017).

33. Peng, Y. et al. A versatile MOF-based trap for heavy metal ion capture and dispersion. Nat. Commun. 9, 187 (2018).

34. Zhao, X. et al. The stability and defluoridation performance of MOFs in fluoride solutions. Microporous Mesoporous Mater. 185, 72-78 (2014).

35. Lin, K. Y., Liu, Y. T. \& Chen, S. Y. Adsorption of fluoride to UiO-66-NH in water: Stability, kinetic, isotherm and thermodynamic studies. J. Colloid Interface Sci. 461, 79-87 (2016).

36. He, J. et al. Performance of a novelly-defined zirconium metal-organic frameworks adsorption membrane in fluoride removal. J. Colloid Interface Sci. 484, 162-172 (2016).

37. Bai, Y. et al. Zr-based metal-organic frameworks: design, synthesis, structure, and applications. Chem. Soc. Rev. 45, 2327-2367 (2016).

38. Wang, J. et al. Oscillatory reaction induced periodic C-quadruplex DNA gating of artificial ion channels. ACS Nano. 11, 3022-3029 (2017).

39. Gómez-Gualdrón, D. A., Moghadam, P. Z., Hupp, J. T., Farha, O. K. \& Snurr, R. Q. Application of consistency criteria to calculate bet areas of microand mesoporous metal-organic frameworks. J. Am. Chem. Soc. 138, 215-224 (2015).

40. Shearer, G. C. et al. Defect engineering: tuning the porosity and composition of the metal-organic framework UiO-66 via modulated synthesis. Chem. Mater. 28, 3749-3761 (2016).

41. Nightingale, E. R. Phenomenological theory of ion solvation. Eff. Radii Hydrated Ions. J. Phys. Chem. A 63, 1381-1387 (1959).

42. Klet, R. C., Liu, Y., Wang, T. C., Hupp, J. T. \& Farha, O. K. Evaluation of bronsted acidity and proton topology in $\mathrm{Zr}$ - and Hf-based metal-organic frameworks using potentiometric acid-base titration. J. Mater. Chem. A 4, 1479-1485 (2016).

43. Adamson, A. W. Chapter twelve-solutions of electrolytes. A textbook of physical chemistry. 2nd edn. (Academic Press, Cambridge, 1979).

44. Zhang, H. et al. Ultrafast selective transport of alkali metal ions in metal organic frameworks with subnanometer pores. Sci. Adv. 4, eaaq0066 (2018).

45. Anderson, R., Schweitzer, B., Wu, T., Carreon, M. A. \& Gomez-Gualdron, D. A. Molecular simulation insights on $\mathrm{Xe} / \mathrm{Kr}$ separation in a set of nanoporous crystalline membranes. ACS Appl. Mater. Interfaces 10, 582-592 (2017).

46. Verploegh, R. J., Nair, S. \& Sholl, D. S. Temperature and loading-dependent diffusion of light hydrocarbons in ZIF-8 as predicted through fully flexible molecular simulations. J. Am. Chem. Soc. 137, 15760-15771 (2015).

47. Williams, C. D., Dix, J., Troisi, A. \& Carbone, P. Effective polarization in pairwise potentials at the graphene-electrolyte interface. J. Phys. Chem. Lett. 8 703-708 (2017).

48. Gross, K. C. \& Seybold, P. G. Substituent effects on the physical properties and $\mathrm{pKa}$ of aniline. Int. J. Quantum Chem. 80, 1107-1115 (2000). 
49. Liu, J., Cheng, L., Liu, B. \& Dong, S. Covalent modification of a glassy carbon surface by 4 -aminobenzoic acid and its application in fabrication of a polyoxometalates-consisting monolayer and multilayer films. Langmuir 16, 7471-7476 (2000).

50. Hollingsworth, C. A., Seybold, P. G. \& Hadad, C. M. Substituent effects on the electronic structure and $\mathrm{pKa}$ of benzoic acid. Int. J. Quantum Chem. 90, 1396-1403 (2002).

51. Yang, Q. et al. Understanding the thermodynamic and kinetic behavior of the $\mathrm{CO}_{2} / \mathrm{CH}_{4}$ gas mixture within the porous zirconium terephthalate UiO-66 $(\mathrm{Zr})$ : a joint experimental and modeling approach. J. Phys. Chem. C. 115, 13768-13774 (2011).

52. Lee, S. H. \& Rasaiah, J. C. Molecular dynamics simulation of ion mobility. 2. Alkali metal and halide ions using the SPC/E model for water at $25^{\circ} \mathrm{C}$. J. Phys. Chem. 100, 1420-1425 (1996).

53. Lee, S. H. \& Rasaiah, J. C. Molecular dynamics simulation of ionic mobility. I. Alkali metal cations in water at $25^{\circ} \mathrm{C}$. J. Phys. Chem. 101, 6964-6974 (1994).

54. Wen, Q. et al. Highly selective ionic transport through subnanometer pores in polymer films. Adv. Funct. Mater. 26, 5796-5803 (2016).

55. Carvajal-Diaz, J. A. \& Cagin, T. Electrophoretic transport of $\mathrm{Na}^{+}$and $\mathrm{K}^{+}$ ions within cyclic peptide nanotubes. J. Phys. Chem. B 120, 7872-7879 (2016).

56. Hartkamp, R., Siboulet, B., Dufrêche, J.-F. \& Coasne, B. Ion-specific adsorption and electroosmosis in charged amorphous porous silica. Phys. Chem. Chem. Phys. 17, 24683-24695 (2015).

57. Ge, Y., Xu, D., Yang, J., Chen, Y. \& Li, D. Ionic current through a nanopore three nanometers in diameter. Phys. Rev. E 80, 021918 (2009).

58. Qiao, R. \& Aluru, N. Scaling of electrokinetic transport in nanometer channels. Langmuir 21, 8972-8977 (2005).

59. Hu, G., Mao, M. \& Ghosal, S. Ion transport through a graphene nanopore. Nanotechnology 23, 395501 (2012).

60. Suk, M. E. \& Aluru, N. Ion transport in sub-5-nm graphene nanopores. J. Chem. Phys. 140, 084707 (2014).

61. Yang, K.-L., Yiacoumi, S. \& Tsouris, C. Canonical monte carlo simulations of the fluctuating-charge molecular water between charged surfaces. J. Chem. Phys. 117, 337-345 (2002).

62. Fiorin, G., Klein, M. L. \& Hénin, J. Using collective variables to drive molecular dynamics simulations. Mol. Phys. 111, 3345-3362 (2013).

63. Grossfield, A. Wham: the weighted histogram analysis method. Version 2, 06 (2012).

64. Camp, J. S. \& Sholl, D. S. Transition state theory methods to measure diffusion in flexible nanoporous materials: Application to a porous organic cage crystal. J. Phys. Chem. C. 120, 1110-1120 (2016).

65. Apel, P. Y., Blonskaya, I. V., Orelovitch, O. L., Ramirez, P. \& Sartowska, B. A. Effect of nanopore geometry on ion current rectification. Nanotechnology 22, 175302 (2011).

66. Zhang, H. et al. Bioinspired artificial single ion pump. J. Am. Chem. Soc. 135, 16102-16110 (2013).

\section{Acknowledgements}

This work was supported by the Australian Government Department of Industry, Innovation, and Science through the Australia-China Science and Research Fund (ACSRF48154) and is conducted as part of the research program of the Australia-
China Joint Research Centre in Future Dairy Manufacturing. This research was also supported by the Australian Research Council (DP150100765, DP180100298 and DE170100006). B.D.F.'s work in preparing this manuscript was supported as part of the Center for Materials for Water and Energy Systems (M-WET), an Energy Frontier Research Center funded by the U.S. Department of Energy, Office of Science, Office of Basic Energy Sciences under Award Number DE-SC0019272. The assistance of Ms. Pam Cook in editing the manuscript is also gratefully acknowledged.

\section{Author contributions}

X.L. and H.Z. contributed equally to this work. H.Z. and H.W. conceived and designed the project. H.Z. and X.L. designed the experiments, and X.L., J.H. and J.L. performed the experiments and the related characterization. C.D.E. did the XPS and data analysis J.Z.L. and P.W. performed the molecular dynamics simulations. H.Z. and X.L. analyzed the data and wrote the paper. H.Z., H.W., M.R.H., J.Z.L., P.W. and X.L. revised the manuscript. X.Z., A.W.T., B.D.F., A.J.H. and L.J. discussed the results and commented on the manuscript.

\section{Additional information}

Supplementary information accompanies this paper at https://doi.org/10.1038/s41467019-10420-9.

Competing interests: H.Z., H.W., X.L., J.L., B.D.F. and A.J.H. are inventors on an international patent application related to this work filed by Monash University (Application No: PCT/AU2018/051341, filed 14 Dec 2018). The authors declare no competing interest.

Reprints and permission information is available online at http://npg.nature.com/ reprintsandpermissions/

Journal peer review information: Nature Communications thanks the anonymous reviewers for their contribution to the peer review of this work.

Publisher's note: Springer Nature remains neutral with regard to jurisdictional claims in published maps and institutional affiliations.

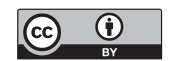

Open Access This article is licensed under a Creative Commons Attribution 4.0 International License, which permits use, sharing, adaptation, distribution and reproduction in any medium or format, as long as you give appropriate credit to the original author(s) and the source, provide a link to the Creative Commons license, and indicate if changes were made. The images or other third party material in this article are included in the article's Creative Commons license, unless indicated otherwise in a credit line to the material. If material is not included in the article's Creative Commons license and your intended use is not permitted by statutory regulation or exceeds the permitted use, you will need to obtain permission directly from the copyright holder. To view a copy of this license, visit http://creativecommons.org/ licenses/by/4.0/.

(C) The Author(s) 2019 